Central Washington University

ScholarWorks@CWU

All Faculty Scholarship for the College of the Sciences

$12-8-2005$

\title{
Estimation of iron solubility from observations and a global aerosol model
}

Chao Luo

N. M. Mahowald

N. Meskhidze

Y. Chen

R. L. Siefert

See next page for additional authors

Follow this and additional works at: https://digitalcommons.cwu.edu/cotsfac

Part of the Atmospheric Sciences Commons, Chemistry Commons, Geophysics and Seismology Commons, Marine Biology Commons, and the Oceanography Commons 


\section{Authors}

Chao Luo, N. M. Mahowald, N. Meskhidze, Y. Chen, R. L. Siefert, A. R. Baker, and Anne M. Johansen 


\title{
Estimation of iron solubility from observations and a global aerosol model
}

\author{
Chao Luo, ${ }^{1}$ N. M. Mahowald, ${ }^{2}$ N. Meskhidze, ${ }^{3}$ Y. Chen, ${ }^{4}$ R. L. Siefert, ${ }^{4}$ A. R. Baker, ${ }^{5}$ \\ and A. M. Johansen ${ }^{6}$ \\ Received 9 April 2005; revised 19 August 2005; accepted 26 September 2005; published 8 December 2005.
}

[1] Mineral aerosol deposition is the dominant source of iron to the open ocean. Soil iron is typically insoluble and understanding the atmospheric processes that convert insoluble iron to the more soluble forms observed over the oceans is crucial. In this paper, we model several proposed processes for the conversion of $\mathrm{Fe}(\mathrm{III})$ to $\mathrm{Fe}(\mathrm{II})$, and compare with cruise observations. The comparisons show that the model results in similar averaged magnitudes of iron solubility as measured during 8 cruises in 2001-2003. Comparisons show that results of cases including cloud, $\mathrm{SO}_{2}$ and hematite processing are better than the other approaches used using the reaction rates we assume in this paper; unfortunately the reaction rates are not well known, and this hampers our ability to conclusive show one process is more likely than another. The total soluble iron deposited to the global ocean is estimated by the model to range from 0.36 to $1.6 \mathrm{Tg} \mathrm{y}^{-1}$, with $0.88 \mathrm{Tg} \mathrm{y}^{-1}$ being the mean estimate; however there are large uncertainties in these estimates. Comparison shows that the regions with largest differences between the model simulations and observations of iron solubility are in the Southern Atlantic near South America coast and North Atlantic near Spain coast. More observations in these areas or in the South Pacific will help us identify the most important processes. Additionally, laboratory experiments that constrain the reaction rates of different compounds that will result in a net solubilization of iron in aerosols are required to better constrain iron processing in the atmosphere. Additionally, knowing what forms of iron are most bioavailable will assist atmospheric scientists in providing better budgets of iron deposited to the ocean surfaces.

Citation: Luo, C., N. M. Mahowald, N. Meskhidze, Y. Chen, R. L. Siefert, A. R. Baker, and A. M. Johansen (2005), Estimation of iron solubility from observations and a global aerosol model, J. Geophys. Res., 110, D23307, doi:10.1029/2005JD006059.

\section{Introduction}

[2] Iron is a critical nutrient for organisms in the ocean because of its role in primary productivity [Zhuang et al., 1990]. Iron has been hypothesized to limit phytoplankton productivity in high nitrate low-chlorophyll (HNLC) ocean regions [Martin et al., 1991]. In these regions, chlorophyll levels are lower than expected because low concentrations of iron restrict the growth of phytoplankton and limit primary production [Martin et al., 1991]. Deposition of

\footnotetext{
${ }^{1}$ Institute for Computational Earth System Science, University of California, Santa Barbara, California, USA.

${ }^{2}$ National Center for Atmospheric Research, Boulder, Colorado, USA.

${ }^{3}$ School of Earth and Atmospheric Science, Georgia Institute of Technology, Atlanta, Georgia, USA.

${ }^{4}$ Chesapeake Biological Laboratory, University of Maryland Center for Environmental Science, Solomons, Maryland, USA. UK.

${ }^{5}$ School of Environmental Science, University of East Anglia, Norwich,

${ }^{6}$ Department of Chemistry, Central Washington University, Ellensburg, Washington, USA.
}

Copyright 2005 by the American Geophysical Union. 0148-0227/05/2005JD006059 iron to these regions has important implications for the $\mathrm{CO}_{2}$ budget, as increases in iron to the oceans may result in a decrease of $\mathrm{CO}_{2}$ in the atmosphere on glacial time scales [Watson et al., 1994; Cooper et al., 1996; Lefevre and Waterson, 1999]. Additionally, nitrogen fixing organisms (diazotrophs) in the ocean are thought to have higher iron requirements than most ocean biota, and the high iron inputs to the North Atlantic may be related to the high nitrogen fixation in that ocean basin [Falkowski et al., 1998]. It also has been proposed that iron in marine aerosols may affect the sulfur cycle through oxidation reactions [Zhuang et al., 1992] and in turn the climate feedback loop through dimethyl sulfide (DMS) oxidation and cloud condensation nuclei formation [Charlson et al., 1987; Turner et al., 1996].

[3] The biogeochemical processes involving iron in the ocean are thought to be dependent upon the solubility of iron, which is a function of the oxidation state of iron along with its mineralogy. On average, desert dust aerosols contain 3.5\% iron [Duce and Tindale, 1991], primarily as ferric iron (Fe(III)) in aluminosilicate form [Zhu et al., 1997]. This form of $\mathrm{Fe}$ is insoluble in high $\mathrm{pH}$ solutions such as seawater [Stumm and Morgan, 1981; Zhu et al., 
1992]; although some studies have suggested that ocean biota can use Fe(III) [Barbeau et al., 2001]. Studies of the solubility of soils suggest that, iron solubility is on average $\sim 0.6 \%$ (extracted at a pH of 4.65) [Fung et al., 2000; Sillanpaa, 1982], while observations show much higher iron solublities in aerosols over the ocean [e.g., Zhu et al., 1992, 1997], implying that atmospheric processing of mineral aerosols is important for increasing iron availability. Photochemical processes reducing iron to a more soluble state (Fe(II)) have been the focus of several experimental studies [Zuo and Hoigne, 1992; Pehkonen et al., 1993; Siefert et al., 1994; Zuo, 1995; Saydam and Senyuva, 2002]. The steady-state concentrations of $\mathrm{Fe}(\mathrm{II})$ are strongly depending on the $\mathrm{pH}$ of solution and the available solar radiation [Zuo and Hoigne, 1992]. The enhanced levels of $\mathrm{Fe}(\mathrm{II})$ in the fine mode as observed by Siefert et al. [1999] and Johansen et al. [2000] suggest that atmospheric transport may play a role in the size segregation of $\mathrm{Fe}(\mathrm{II})$, as large particles are selectively removed due to gravitational settling [Hand et al., 2004]. It is important to note that it is not well known what forms of iron are bioavailable, and here we assume that bioavailable iron is soluble Fe(II) iron, and we show also labile Fe(II) and Fe(III) distributions.

[4] Hand et al. [2004] made a first attempt to model iron solubility using simple cloud processing and radiative processing schemes using a subset of the observations we use in this paper. Here we repeat the same cloud and radiative processes experiments, but also add in processing by sulfate and organic acid aerosols. Iron solubility from the model is compared with measurements of fine and coarse mode aerosol measured on-board cruise in the Atlantic and Pacific Oceans during 2001-2003.

[5] This paper is organized in five sections. Section 2 briefly describes the observations used in this study. Section 3 describes global aerosols transport model, and iron solubility model. Section 4 includes results and discussion and section 5 summarizes the results of the study.

\section{Observations of Iron Solubility}

[6] Measurements of iron solubility have been taken in several different ocean basins in recent years. We focus here on using eight cruises occurring between 2001 and 2003 in the Atlantic and Pacific Oceans [Chen and Siefert, 2003, 2004] for which we conduct a modeling study, but also show results from an Indian Ocean cruise from 1997, an Atlantic cruise from 1996 [Johansen et al., 2000] and two Atlantic cruises from 2000 and 2001 [Baker et al., 2003; Baker, 2004].

[7] For the MP01-MP09 cruises (Atlantic and Pacific cruises in 2001, 2002 and 2003) and the 1996 Atlantic cruise and 1997 Indian Ocean cruise, aerosol measurements were performed on-board using size resolved samplers to separate fine (diameter, $\mathrm{Dp}<3 \mathrm{um}$ ) and coarse (Dp $>3 \mathrm{um}$ ) aerosol composition, following the method outlined in Siefert et al. [1999], Chen and Siefert [2004], and Johansen et al. [2000]. The labile Fe(II), in both the fine and coarse particles collected on the two filters, were determined by a sequential extraction procedure. These measurements were initiated immediately (within 1 hour) after sample collection in order to minimize any changes in Fe oxidation state due to possible redox reactions occurring during sample storage. Three labile fractions of Fe were quantified using the procedure: (1) aqueous-labile-Fe(II) (Fe(II)aq,labile), (2) 5-min Ferrozine-labile-Fe(II) (Fe(II)FZ,5min), and (3) 22-hour ferrozine-labile-Fe(II) (Fe(II)FZ,22h,labile). Total labile iron $\mathrm{Fe}$ (II) (Fe(II) total,labile) is defined as the sum of these three fractions. Fe(II) concentrations were determined colorimetrically by complexation with ferrozine [Stookey, 1970] and subsequent absorption measurements using a portable spectrophotometer. Total Fe concentrations were measured in both the coarse and fine fractions of the atmospheric aerosol (using the filters from the HVDVI (High Volume Dichotomous virtual Impact). The method included a strong acid digestion of the aerosol samples, and subsequent analysis using inductively coupled plasma mass spectrometry (ICP-MS) with a Hewlett-Packard 4500 instrument. The same samples were also analyzed on a Perkin Elmer/Sciex 6000 ICP-MS for Fe for quality control [Siefert et al., 1999].

[8] For the James Clark Ross (JCR) and Polarstern cruises in the Atlantic in 2000 and 2001, the soluble iron was measured following [Sarthou et al., 2003]. The aerosol samplers were collected using high volume $\left(1 \mathrm{~m}^{3} / \mathrm{min}\right)$ aerosol collectors [Baker et al., 2003]. Two collectors were used to provide paired samples for trace metal (TM) and major iron (MI) analysis. The collectors were equipped with cascade impactors for size segregation of the aerosol. Results are reported in term of a size split of $1 \mu \mathrm{m}$ (impactor stages $3 \& 4 \mathrm{D}_{\mathrm{p}}>1 \mu \mathrm{m}$, backup filter $\mathrm{Dp}<1 \mathrm{um}$ ), as this represents the boundary between the so-called accumulation mode particles that are generated in the atmosphere by gasparticle conversions and the coarse material whose source is mechanical (e.g. soil-derived dust, sea-spray particles) [Raes et al., 2000]. Aerosol collection substrates (slotted and backup filters) were all Whatman 41 paper. Those used for TM sampling were acid-washed before use, while MI sampling was conducted with untreated substrates.

[9] Total and soluble Fe were extracted from fractions of the TM aerosol samples. Soluble Fe was extracted using an ammonium acetate leach at $\mathrm{pH} 4.7$ for 1-2 hours [Sarthou et $a l ., 2003]$, and determined by graphite furnace atomic absorption spectroscopy (GFAAS). A strong acid $\left(\mathrm{HNO}_{3} / \mathrm{HF}\right)$ digestion procedure followed by inductively coupled plasma - optical emission spectrometry analysis was used to determine total Fe. Major ions (including $\mathrm{Na}^{+}$and $\mathrm{SO}_{4}^{2-}$ ) were determined by ion chromatography after extraction of a quarter of the MI filters in ultra pure water with one hour of ultrasonic agitation. Full analytical details for all these procedures can be found elsewhere [Baker, 2004]. $\mathrm{Na}^{+}$data were used to calculate the component of aerosol $\mathrm{SO}_{4}^{2-}$ concentrations arising from non-seasalt (nss $\mathrm{SO}_{4}$ ) sources by assuming that aerosol $\mathrm{Na}^{+}$was derived exclusively from sea spray [see Baker, 2004].

[10] More detailed information about the methodology for measuring iron and other constituents are found in the data description papers for each cruise [Chen and Siefert, 2003, 2004; Baker et al., 2005; Johansen et al., 2000]. Labile iron (II and III) is operationally defined as the portion of iron, which is released after $4.2 \mathrm{pH}$ leaching and after 22 hours of ferrozine addition for most of the data (except the JCR and Polarstern cruises) [Siefert et al., 1999]. For the JCR and Polarstern cruises, we assume the 'soluble Fe' fraction is similar to the labile iron (II and III) measurement 
from the other cruises. Note that these different measurement techniques may not be completely consistent. For most of our analysis, we use the consistent measurements taken during 2001-2003 of Fe(II) [Chen and Siefert, 2003, 2004].

[11] Figure 1 shows the spatial distribution of percentage iron solubility in the fine and coarse mode as observed in these limited observations, where we define iron solubility as both $\mathrm{Fe}(\mathrm{II}) / \mathrm{Fe} * 100$ (Figures $1 \mathrm{a}$ and $1 \mathrm{~b}$ ) and as labile $\mathrm{Fe}$ (II and III)/Fe $/ 100$ (Figures $1 \mathrm{c}$ and $1 \mathrm{~d}$ ). The observations show that fine mode iron solubility is higher than coarse mode solubility [e.g., Siefert et al., 1999; Johansen et al., 2000; Baker et al., 2005]. Additionally, there is some tendency for the largest solubilities to occur far from the source areas (e.g. western tropical Atlantic, mid-latitude North and South Atlantic), consistent with atmospheric processing of the iron, or alternatively with anthropogenic sources of iron. For this study, we will assume the iron is dominantly from desert dust, similar to other studies [Mahowald et al., 2005].

[12] These observations suggest high iron solubilities in regions with relatively little pollution (e.g. South Atlantic). The average percents of labile Fe solubilities (labile $\mathrm{Fe} / \mathrm{Fe}$ * $100)$ are $10.3 \%, 1.34 \%$ and $7.68 \%$ for fine mode aerosols in the Atlantic, Indian and Pacific oceans respectively, and average percents of labile Fe solubility are $5.45 \%, 0.20 \%$ and $15.9 \%$ for coarse mode in Atlantic, Indian and Pacific ocean basin respectively for the data shown on Figure 1. Using only one consistent dataset of MP01-MP09 observed in Atlantic and Pacific Basins, the average percents of Fe(II) solubility $(\mathrm{Fe}(\mathrm{II}) / \mathrm{Fe} * 100)$ are $3.72 \%$, and $4.50 \%$ for fine mode in Atlantic and Pacific, and $1.90 \%$ and $4.45 \%$ for coarse mode in the Atlantic and Pacific ocean basins, respectively. Observations of iron in seawater have suggested larger iron solubilities in the Pacific than the tropical Atlantic [Boyle et al., 2005]. It is unclear from the aerosol data presented here whether the aerosols in the tropical Atlantic or Pacific have greater iron solubilities. Additionally, more work is necessary to deduce how the iron solubility as measured in the atmosphere (either Fe(II) or labile Fe fraction) relates to the fraction that dissolves into the ocean and/or the fraction that is bioavailable in the ocean.

[13] Sulfate or oxalate could change the solubility of iron. Laboratory studies have shown that reaction of sulfate [ $\mathrm{Zhu}$ et al., 1992] can change the solubility of iron, so we explore the relationship between iron and these compounds here. Figure 2 and Table 1 show the relationship between observed sulfate and oxalate against iron solubility defined as either Fe(II) or labile iron. Although for some cruises there are relationships, overall, across all cruises, there is no statistically significant relationship between the iron solubility and either the sulfate or the oxalate in the observations, similar to Hand et al. [2004]. We will explore our expected relationship from a model in a later section, and draw conclusions from the observed and modeled results of relationships between sulfate and oxalic acid. Also shown in Figure 2 are the relationships between $\mathrm{Fe}(\mathrm{II})$ and labile iron as defined in this study. The average fine mode $\mathrm{Fe}(\mathrm{II}) / \mathrm{Fe}$ ratio is $0.035 \pm 0.069$, while for labile $\mathrm{Fe} / \mathrm{Fe}$ the ratio is $0.075 \pm 0.100$. The average $\mathrm{Fe}(\mathrm{II}) / \mathrm{Fe}$ ratio in the coarse mode is $0.015 \pm 0.030$ and the average labile $\mathrm{Fe} / \mathrm{Fe}$ is $0.041 \pm$ 0.073 . There is a correlation coefficient of 0.94 and 0.83 between $\mathrm{Fe}(\mathrm{II}) / \mathrm{Fe}$ and labile $\mathrm{Fe} / \mathrm{Fe}$ for the fine and coarse mode, respectively. This implies that there is almost twice as much labile $\mathrm{Fe}$ as $\mathrm{Fe}(\mathrm{II})$, but that the solubility defined as either $\mathrm{Fe}(\mathrm{II}) / \mathrm{Fe}$ or labile $\mathrm{Fe} / \mathrm{Fe}$ seem to vary spatially and temporally together (see Figure 3).

[14] Correlations between observed $\mathrm{Fe}(\mathrm{II}) / \mathrm{Fe}$ vs $\mathrm{Fe}$ are -0.24 , and 0.16 for fine and coarse mode respectively, suggesting that there is no clear relationship between soluble iron fraction and total iron. Figure 4 shows the cruise tracks for the 2001-2003 cruises used in the modeldata comparison, and Table 2 shows the time period for each cruise.

\section{Model Description}

[15] The chemical transport model used to simulate aerosols and dust is the Model of Atmospheric Transport and Chemistry (MATCH, version 4.2) [Rasch et al., 1997], driven by NCEP analysis dataset [Kistler et al., 2001; Mahowald et al., 1997]. The horizontal resolution of the model is T62 $(\sim 1.9 \times 1.9$ degree $)$, and 28 vertical levels from surface to $10 \mathrm{mb}$ (the same as the resolution of the NCEP reanalysis made available at NCAR).

\subsection{Aerosol Model Description}

[16] The mineral aerosols sources are calculated using the Desert Entrainment And Deposition (DEAD) model [Zender et al., 2003]. This mobilization scheme is based on the wind tunnel and in situ studies of Iversen and White [1982], Marticorena and Bergametti [1995], Gillette et al. [1997], and Fecan et al. [1999]. It is similar to those used in Tegen and Fung [1994], Mahowald et al. [1999], Guelle et al. [2000], Ginoux et al. [2001], and Tegen et al. [2002] in that it is based on a wind threshold velocity and has a wind speed cubed relationship for dust mobilization, but the details of the mobilization are slightly different in each case. The DEAD module mobilization scheme [Zender et $a l ., 2003$ ] is based on the friction velocity (wind stress at the surface), consistent with the original derivations [e.g., Gillette and Passi, 1988]. The wind stress is a function of the wind speed, roughness length and the atmospheric stability at the surface. The surface roughness length in dust producing regions is set to the globally uniform value of $100 \mu \mathrm{m}$, a value typical of erodible soil beds [Gillette et al., 1997] than the large-scale roughness lengths for bare ground $(\sim 5 \mathrm{~cm})$ used in general circulation models [e.g., Bonan, 1996]. The mass flux of saltating particles depends on the excess of the wind friction speed over the threshold wind friction velocity for saltation. More details about the source parameterizations are available in Zender et al. [2003] and Luo et al. [2003]. In this study, we follow Ginoux et al. [2001], Zender et al. [2003], and Mahowald et al. [2002], and assume that all topographic lows with little vegetation and low soil moisture are dust sources, using the time independent source area from Ginoux et al. [2001], which includes only non-vegetated low-lying regions. There is some debate about the anthropogenic sources of desert dust [e.g., Prospero et al., 2002; Mahowald et al., 2002; Luo et al., 2003; Mahowald and Luo, 2003; Mahowald and Dufresne, 2004; Tegen et al., 2004], however modeling studies have indicated the low sensitivity of downwind concentrations to the exact location of sources 
$\mathrm{Fe}(\mathrm{II}) / \mathrm{Fe}$ (total) \%, fine

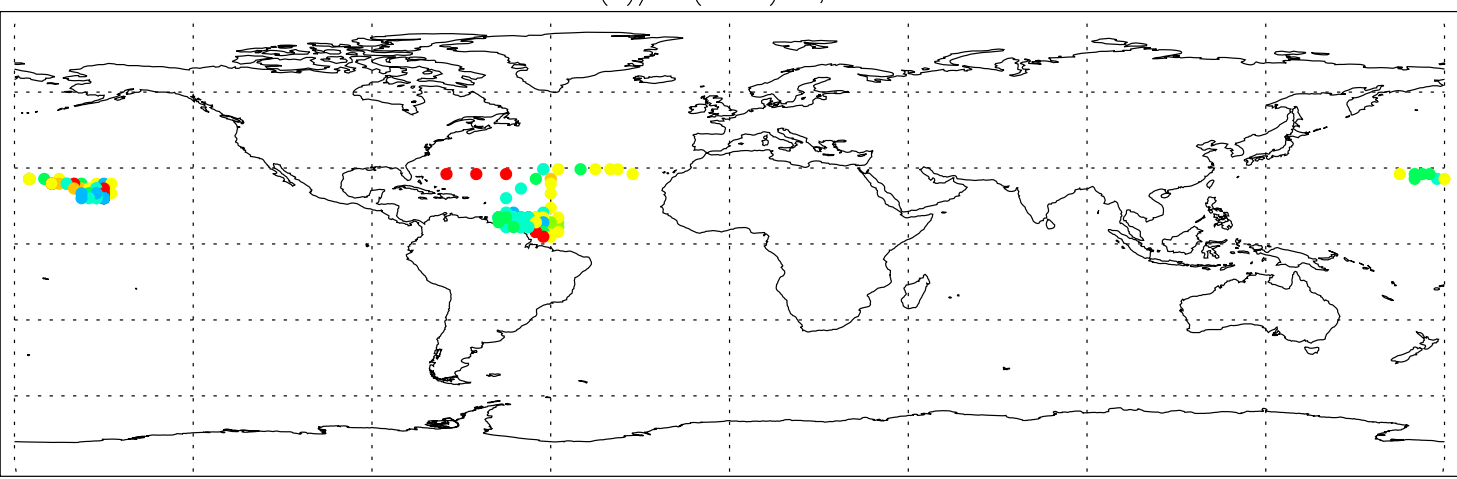

$\mathrm{Fe}(\mathrm{II}) / \mathrm{Fe}($ total) $\%$, corase

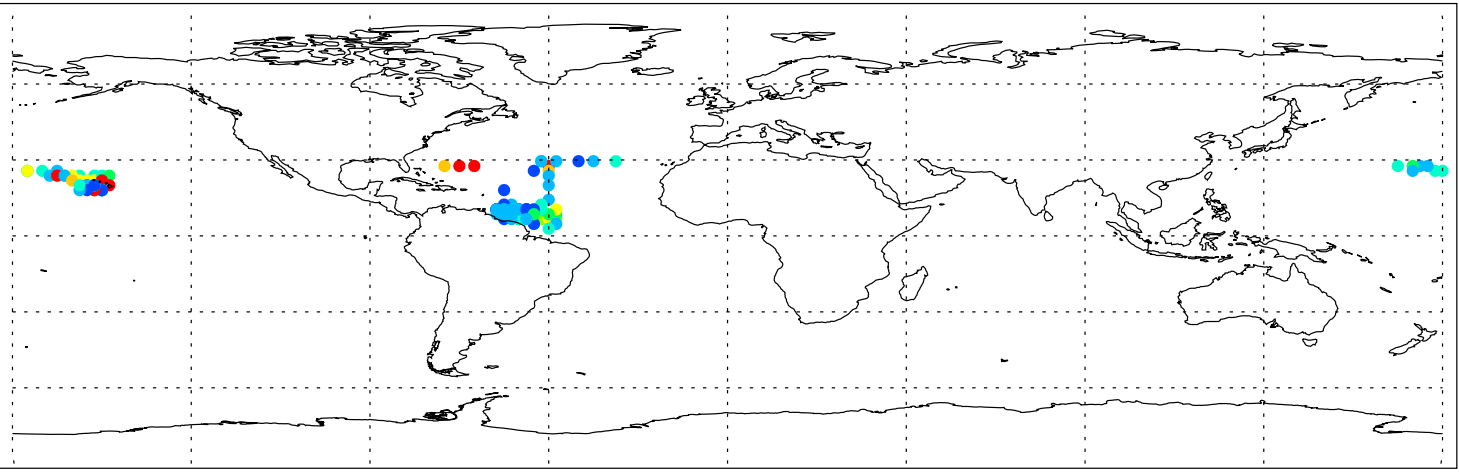

Labile $\mathrm{Fe} / \mathrm{Fe}$ (total) \%, fine

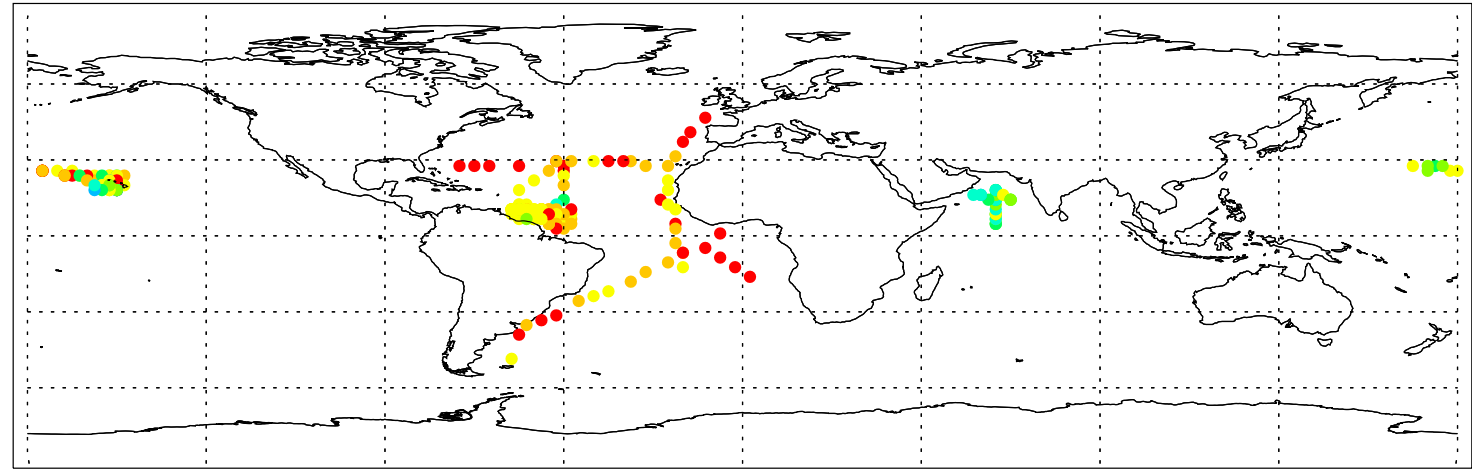

Labile $\mathrm{Fe} / \mathrm{Fe}$ (total) \%, coarse
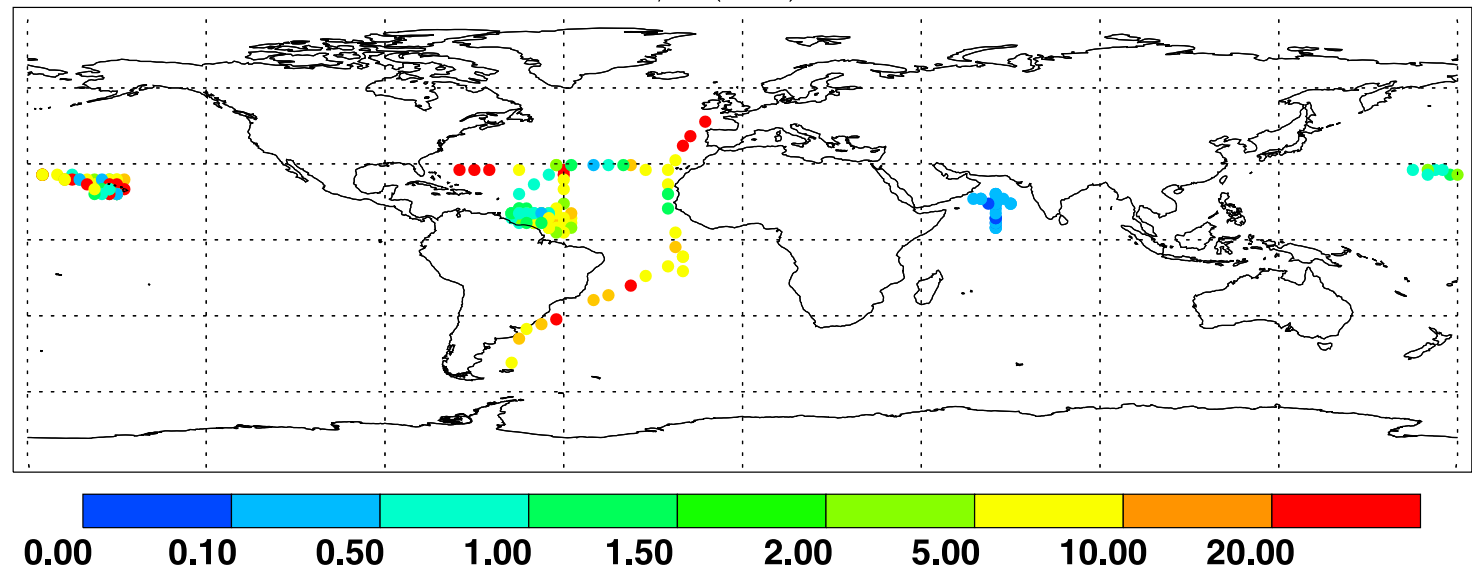

Figure 1. Observations of iron solubility in percentages, defined as $\mathrm{Fe}(\mathrm{II}) / \mathrm{Fe}($ total) $* 100 \%$ and Labile $\mathrm{Fe} / \mathrm{Fe}$ (total) $* 100 \%$, from the cruises described in the text. 

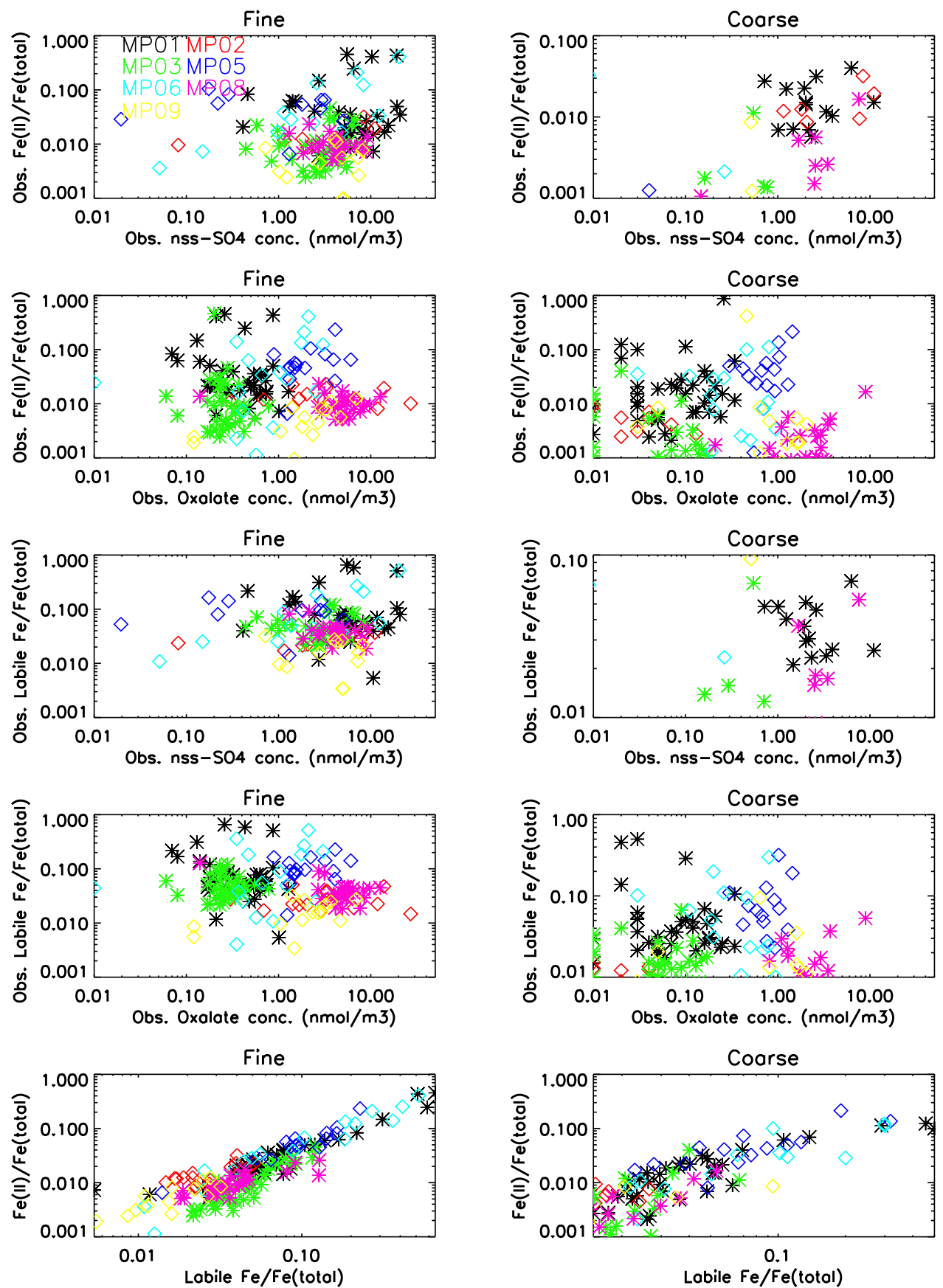

Figure 2. Scatterplots showing the relationship between observed iron solubility (defined as Fe(II)/ $\mathrm{Fe}$ (total) * $100 \%$ and Labile $\mathrm{Fe} / \mathrm{Fe}$ (total) * $100 \%$ ) and observed $\mathrm{SO}_{4}$ and oxalate for fine and coarse mode aerosols, and the relationship between Fe(II) and labile Fe. Stars represent Atlantic cruises and rectangles represent Pacific cruises.

[e.g., Mahowald et al., 2002; Luo et al., 2003]. We chose a globally constant particle size distribution; the fractions are 0.1 for the class $0.1-1 \mu \mathrm{m}$, and .3 for the classes $1-2.5$, 2.5-5.0, and 5.0-10 $\mu \mathrm{m}$, where the sizes are diameters of the particle. Within each bin we assume log normal distributions in aerosol sizes [Zender et al., 2003].

[17] Both dry deposition and wet deposition are included as loss processes for all aerosols [Rasch et al., 1997]. Dry depositional processes for dust aerosol are simulated following Seinfeld and Pandis [1996] and include turbulent deposition and gravitational settling, with the latter dominating for large particles.

[18] The model also simulates sources, simple chemistry and deposition of sulfur aerosols, carbonaceous aerosols, and sea salt aerosols [Barth et al., 2000; Rasch et al., 2000]. Emissions of sulfur species in the model include anthropogenic emissions of $\mathrm{SO}_{2}$ and $\mathrm{SO}_{4}$ and oceanic emissions of dimethyl sulfide (DMS). Anthropogenic emissions were obtained from the Global Emissions Inventory Activity (GEIA) emission inventory [Benkovitz et al., 1996], which 
Table 1. Correlation Between Observed Sulfate, Oxalate, and Observed Iron Solubility for Each of the Cruises ${ }^{\mathrm{a}}$

\begin{tabular}{|c|c|c|c|c|c|c|c|c|}
\hline \multirow[b]{2}{*}{ Cruise } & \multicolumn{2}{|c|}{$\begin{array}{c}\text { nss-SO4 } \sim \mathrm{Fe}(\text { sol }) \\
\mathrm{Fe}(\mathrm{II}) / \mathrm{Fe}\end{array}$} & \multicolumn{2}{|c|}{$\begin{array}{c}\text { Oxalate } \sim \mathrm{Fe}(\mathrm{sol}) \\
\mathrm{Fe}(\mathrm{II}) / \mathrm{Fe}\end{array}$} & \multicolumn{2}{|c|}{ nss-SO4 $\sim$ Labile Fe/Fe } & \multicolumn{2}{|c|}{ Oxalate $\sim$ Labile $\mathrm{Fe} / \mathrm{F}$} \\
\hline & Fine & Coarse & Fine & Coarse & & Fine & Coarse & Fine \\
\hline Atlantic & 0.29 & 0.43 & -0.16 & -0.06 & 0.20 & 0.3 & -0.16 & -0.07 \\
\hline MP01 & 0.18 & 0.17 & -0.09 & 0.26 & 0.10 & 0.045 & -0.17 & 0.20 \\
\hline MP03 & -0.17 & -0.02 & -0.11 & -0.28 & 0.16 & -0.15 & -0.11 & -0.17 \\
\hline MP08 & -0.21 & 0.89 & -0.15 & 0.75 & -0.41 & 0.8 & -0.42 & 0.6 \\
\hline Pacific & 0.55 & -0.37 & -0.035 & 0.17 & 0.5 & 0.17 & -0.06 & 0.14 \\
\hline MP02 & 0.62 & - & -0.15 & 0.75 & 0.86 & - & -0.13 & 0.69 \\
\hline MP05 & -0.3 & - & 0.36 & 0.58 & -0.14 & - & 0.34 & 0.35 \\
\hline MP06 & 0.79 & 0.21 & 0.49 & 0.56 & 0.65 & 0.20 & 0.39 & 0.55 \\
\hline MP09 & -0.003 & 0.55 & 0.78 & -0.21 & -0.07 & -0.52 & 0.54 & -0.21 \\
\hline Overall & 0.36 & 0.36 & -0.10 & -0.01 & 0.25 & 0.2 & -0.12 & 0.012 \\
\hline
\end{tabular}

${ }^{a}$ Dashes indicate no data; the nss- $\mathrm{SO}_{4}$ coarse mode related correlations may not be meaningful, since there are fewer data points. Values in bold are significant at $95 \%$.

is representative of 1995 emissions. Distributions of oxidant species (e.g. $\mathrm{OH}, \mathrm{H}_{2} \mathrm{O}_{2}$ and $\mathrm{O}_{3}$ ) come from climatologies [Rasch et al., 2000].

\subsection{Iron Solubility Model Description}

[19] In this paper we simulate the processing of the atmospheric iron to become more soluble using several different approaches. None of these approaches are well constrained, and thus the reaction coefficients have large uncertainties, which may bias or change the results of this study. We try to show here the spatial and temporal distributions associated with different iron processing hypothesis. Insoluble iron becomes more soluble through radiation, cloud, or chemical reactions. $\mathrm{d}[\mathrm{Fe}(\mathrm{II})] / \mathrm{dt}=$ $\mathrm{kFe}(\mathrm{III})$, where $\mathrm{k}$ is rate constant of insoluble iron to soluble iron, and will be discussed for different processes. The chemical reactions of iron are very complex, and not well known, which will limit our ability to conclusively decide which mechanisms appear to dominate in the real atmosphere. Here we separate out mechanisms (photolysis, clouds, sulfur processing) that may be operating at the same time in order to understand the relative importance.

\subsubsection{Radiation Processing (RP)}

[20] To estimate the effects of exposure to solar radiation on iron solubility, we assume that exposing insoluble iron to available solar radiation will result in some conversion to soluble iron during daylight hours as suggested by Siefert et al. [1997] and Zhu et al. [1997]. The possible reaction could be $\mathrm{Fe}(\mathrm{III})+\mathrm{H}_{2} \mathrm{O} \stackrel{h v}{\longrightarrow} \mathrm{Fe}(\mathrm{II})$. In this case we assume there is plenty of water and acidity, but that incoming solar
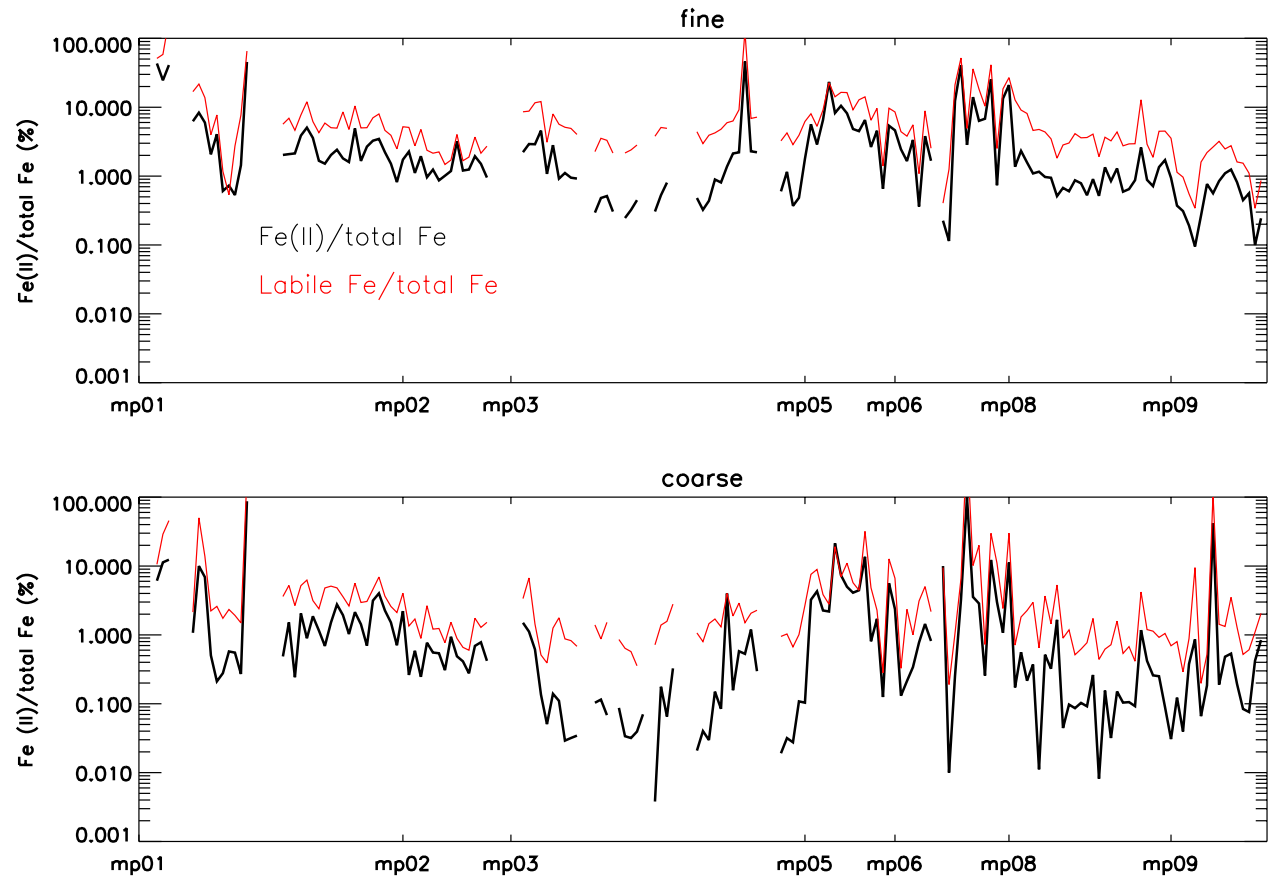

Figure 3. Observed $\mathrm{Fe}(\mathrm{II})$ percentage of iron (Fe(II)/Fe * 100) compared to labile iron percentage (labile $\mathrm{Fe} / \mathrm{Fe} * 100)$. The $\mathrm{X}$-axis represents each cruise observation taken as part of the cruises shown in Figure 4. 

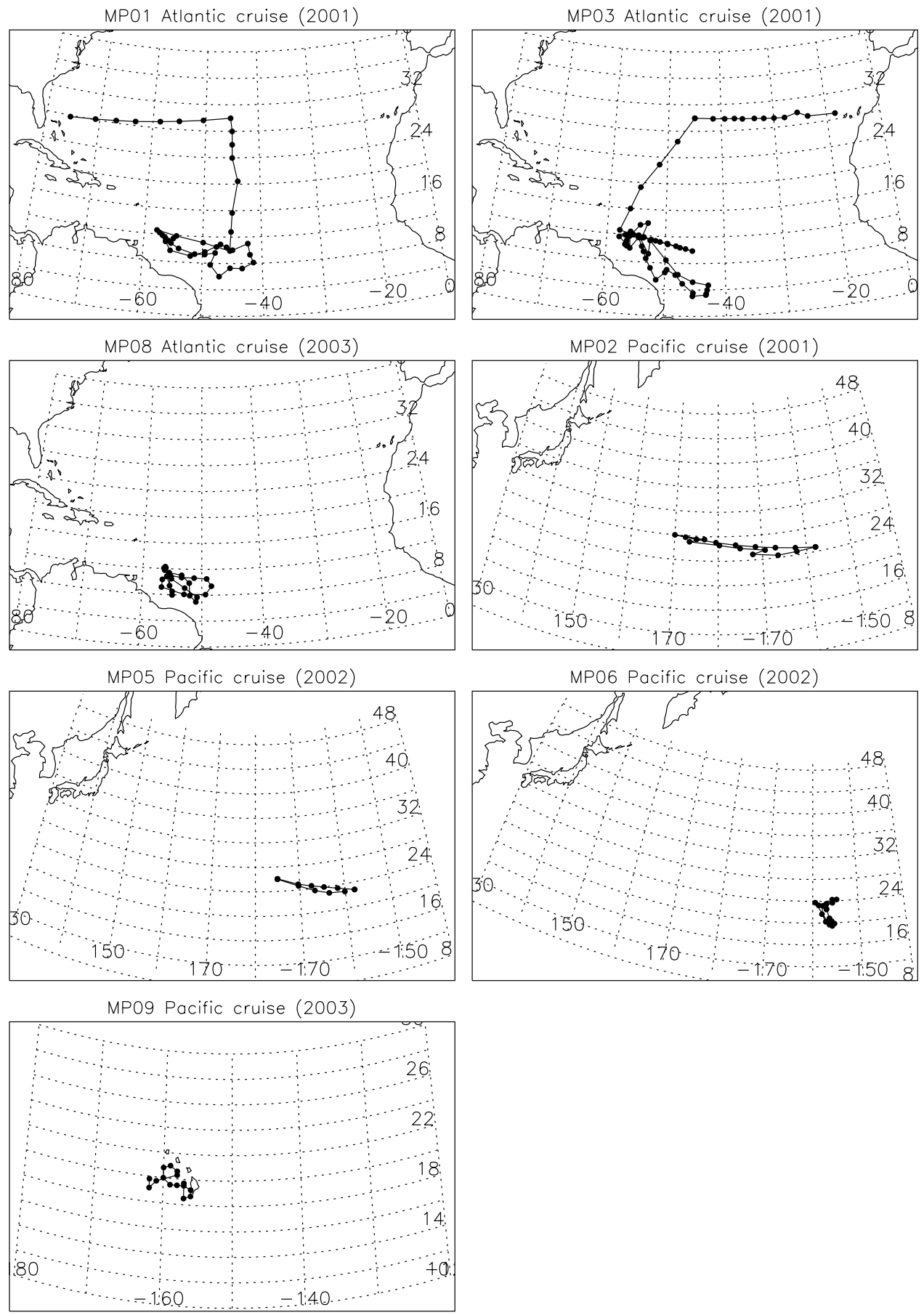

Figure 4. Cruise tracks for the MP01-MP09 observations used for the extensive analysis in the paper.

Table 2. Time Periods of Each Cruise

\begin{tabular}{|c|c|c|c|c|c|c|c|c|}
\hline Cruise & $\begin{array}{c}\text { MP01 } \\
\text { (Atlantic) }\end{array}$ & $\begin{array}{c}\text { MP02 } \\
\text { (Pacific) } \\
\end{array}$ & $\begin{array}{c}\text { MP03 } \\
\text { (Atlantic) }\end{array}$ & $\begin{array}{c}\text { MP05 } \\
\text { (Atlantic) } \\
\end{array}$ & $\begin{array}{c}\text { MP06 } \\
\text { (Pacific) } \\
\end{array}$ & $\begin{array}{c}\text { MP08 } \\
\text { (Pacific) } \\
\end{array}$ & $\begin{array}{c}\text { MP09 } \\
\text { (Pacific) } \\
\end{array}$ & $\begin{array}{c}\text { Polarsterm } \\
\text { and JCR }\end{array}$ \\
\hline $\begin{array}{l}\text { Time } \\
\text { period }\end{array}$ & $\begin{array}{l}1 / 6 / 01- \\
2 / 18 / 01\end{array}$ & $\begin{array}{l}4 / 9 / 01- \\
4 / 26 / 01\end{array}$ & $\begin{array}{r}6 / 26 / 01- \\
8 / 15 / 01\end{array}$ & $\begin{array}{l}7 / 1 / 02- \\
7 / 16 / 02\end{array}$ & $\begin{array}{l}9 / 23 / 02- \\
10 / 15 / 02\end{array}$ & $\begin{array}{r}4 / 18 / 03- \\
5 / 20 / 03\end{array}$ & $\begin{array}{l}8 / 6 / 03- \\
8 / 20 / 03\end{array}$ & $\begin{array}{c}10 / 10- \\
10 / 18,2000 \\
9 / 12 / 01- \\
10 / 21 / 01\end{array}$ \\
\hline Reference & $\begin{array}{c}\text { Chen and } \\
\text { Siefert } \\
{[2003,} \\
2004]\end{array}$ & $\begin{array}{c}\text { Chen and } \\
\text { Siefert } \\
\text { [2003, } \\
\text { 2004] }\end{array}$ & $\begin{array}{c}\text { Chen and } \\
\text { Siefert } \\
{[2003,} \\
2004]\end{array}$ & $\begin{array}{c}\text { Chen and } \\
\text { Siefert } \\
\text { [2004] }\end{array}$ & $\begin{array}{c}\text { Chen and } \\
\text { Siefert } \\
\text { [2004] }\end{array}$ & $\begin{array}{c}\text { Chen and } \\
\text { Siefert } \\
{[2004]}\end{array}$ & $\begin{array}{c}\text { Chen and } \\
\text { Siefert } \\
\text { [2004] }\end{array}$ & $\begin{array}{l}\text { Baker } \\
\quad[2004]\end{array}$ \\
\hline
\end{tabular}


radiation is the main limiter. There were no reaction rates based just on photolysis, in the literature, so we used our observations to make estimates [Hand et al., 2004]. To find an observationally based e-folding decay time scale, we assumed a transport time of 14 days for mineral aerosols to travel across the Atlantic Ocean from desert dust source in Africa to the western Atlantic cruise locations [e.g., Husar et al., 1997], where there is an average iron solubility of $2-$ $20 \%$ (which means that $98-80 \%$ of the Fe stays as Fe(III)). Assuming a linear decay rate (equation (1)):

$$
A(t)=A(t=0) \bullet \exp \left(-t / \tau_{O B S}\right)
$$

where $\mathrm{A}(\mathrm{t})$ is the $\mathrm{Fe}(\mathrm{III})$ concentration of a parcel, $\mathrm{t}$ is the transit time, and $\tau_{\mathrm{OBS}}$ is the estimated decay lifetime, we can deduce a decay time scale of approximately 300 days, if we assume that $95.5 \%$ of the iron stays as Fe(III) over the 2 week transit time. To make this time scale greater with stronger isolation, we make the decay rate vary with incoming solar radiation $\left(\mathrm{K}_{\mathrm{SR}}\right)$, following equation (2):

$$
K_{S R}(i, j)=\frac{F_{i, j}}{F_{\text {avg }}} / \tau_{O B S}
$$

where $F_{i, j}$ is the shortwave flux at the surface at every location, and $\mathrm{F}_{\mathrm{avg}}$ is the global mean shortwave flux $\left(535.25 \mathrm{Wm}^{-2}\right) \cdot \mathrm{K}_{\mathrm{SR}}(\mathrm{i}, \mathrm{j})$ is then used in the model as the first order decay constant for insoluble iron at location $\mathrm{i}, \mathrm{j}$. Any $\mathrm{Fe}$ (III) lost in from this decay constant is assumed to be converted to $\mathrm{Fe}(\mathrm{II})$, or soluble iron.

\subsubsection{Cloud Processing (CP)}

[21] We estimate the effects of cloud processing on soluble iron by assuming that when insoluble iron came into contact with a cloud, conversion to soluble iron occurs [Siefert et al., 1997; Saydam and Senyuva, 2002]. This case assumes that the clouds are always sufficient acidic to process the iron to become more soluble, and the important process to model is whether the iron is in a cloud or not. The decay rate $\left(\mathrm{K}_{\mathrm{cld}}\right)$ was computed with equation (3):

$$
K_{\text {cld }}(i, j)=\frac{C(i, j)}{C_{\text {avg }}} / \tau_{O B S}
$$

where $\mathrm{C}(\mathrm{i}, \mathrm{j})$ represents the fraction of a grid box that is cloudy in the model at each level, and $\mathrm{C}_{\mathrm{avg}}$ is the average fraction in the tropics around $10^{\circ} \mathrm{N}\left(\mathrm{C}_{\mathrm{avg}}=0.05\right) .(=0.05)$. We picked the tropical cloud fraction because of that is the area of most of the dust transport.

\subsection{3. $\mathrm{SO}_{2}$ Heterogeneous Reaction on Dust Processing} $\left(\mathrm{SO}_{2} \mathrm{P}\right)$

[22] Sulfur reactions with iron can be important in modifying the iron oxidation state. [e.g., Zhu et al., 1992]. We use several approaches to model the sulfur-iron interactions. In this approach, we assume that the $\mathrm{Fe}(\mathrm{III})$ to $\mathrm{Fe}(\mathrm{II})$ conversion rate is proportional to the $\mathrm{SO}_{2}$ heterogeneous reaction rate on the dust surface (equation (4))

$$
\mathrm{Fe}(\mathrm{III})+\mathrm{SO}_{2} \rightarrow \mathrm{Fe}(\mathrm{II})+\mathrm{SO}_{4}
$$

We used the method of Dentener and Crutzen [1993] to calculated the $\mathrm{SO}_{2}$ heterogeneous reaction rate in each grid box $\left(\mathrm{K}_{\mathrm{SO} 2}\right)$ :

$$
K_{S_{2}}=\left(\frac{r}{D_{g}}+\frac{4}{v \gamma}\right)^{-1} A
$$

where $r$ is the dust particle radius, $\mathrm{v}$ is the mean $\mathrm{SO}_{2}$ molecular speed, $\gamma$ is the reaction probability, and $\mathrm{D}_{\mathrm{g}}$ is gas phase diffusion coefficient. A is dust particle surface area, which calculated by

$$
A=V \frac{\int_{0}^{\infty} 3 r^{2}(d N / d r) d r}{\int_{0}^{\infty} r^{3}(d N / d r / d r}
$$

where $\mathrm{N}$ is aerosol number concentration, $\mathrm{V}$ is aerosol volume fraction $\left(\mathrm{cm}^{3}\right.$ aerosol $) /\left(\mathrm{cm}^{3}\right.$ air), assuming all sulfate to be present as ammonium bisulfate, which is calculated by

$$
V=\frac{\chi \cdot D_{\text {air }} \cdot M_{w}}{A \operatorname{vog} \cdot \rho_{\text {aerosol }}}
$$

where $\chi$ is volume mixing ratio of sulfate, $D_{\text {air }}$ is air density (molecules $\mathrm{cm}^{-3}$ ), $\mathrm{M}_{\mathrm{w}}$ is molecular mass of ammonium bisulfate $\left(\mathrm{g} \mathrm{mol}^{-1}\right)$, Avog is Avogadro's number $\left(6.0 \times 10^{23}\right.$ molecules $\left.\mathrm{mol}^{-1}\right)$, and $\rho_{\text {aerosol }}$ is the specific aerosol density $\left(\mathrm{g} \mathrm{cm}^{-3}\right)$. The dust size distribution was assumed to be log-normal [Zender et al., 2003]. The reaction rate between $\mathrm{Fe}(\mathrm{III})$ and $\mathrm{SO}_{2}$ is calculated at every gridbox and time step, and then the insoluble iron, the soluble iron, and the $\mathrm{SO}_{2}$ and $\mathrm{SO}_{4}$ are updated.

\subsection{4. $\mathrm{SO}_{4}$ Heterogeneous Reaction on Dust Processing $\left(\mathrm{SO}_{4} \mathrm{P}\right)$}

[23] In this approach, we assume that the rate converting $\mathrm{Fe}(\mathrm{III})$ to $\mathrm{Fe}$ (II) is proportional to the sulfate concentration $\left(\mathrm{Fe}(\mathrm{III})+\mathrm{H}_{2} \mathrm{O} \stackrel{\mathrm{SO} 4}{\longrightarrow} \mathrm{Fe}(\mathrm{II})_{a q}\right)$. Here we are assuming that the acidity associated with existing sulfate is the limiting process, but we do not know the limit reaction rate. We applied the e-folding timescale of 300 days that fell within the range of values observed in the measurements as calculated in Hand et al. [2004], but allowed it to vary with different sulfate conditions. The rate was computed by equation (8):

$$
K_{S_{4}}(i, j)=\frac{C(i, j)}{C_{a v g}} / \tau_{O B S}
$$

where $\mathrm{K}_{\mathrm{SO} 4}(i, j)$ in units of $\mathrm{s}^{-1}$ is calculated at every grid point $(i, j)$ in the model, $C(i, j)$ is the sulfate concentration at each grid point, and $\mathrm{C}_{\mathrm{avg}}$ is the global mean sulfate concentration. Again, this allows us to estimate a reaction rate dependent on sulfate concentrations that will be roughly consistent with the observations when there are no available reaction rates in the literature.

\subsubsection{Organic Acid Reaction Processing (ORGP)}

[24] Organic acid species effects on the enhancement of soluble iron could be significant [e.g., Zuo and Hoigne, 1992; Zhu et al., 1993; Pehkonen et al., 1993; Siefert et al., 1994; Zuo, 1995]. In this approach, we assume that the reaction rate converting $\mathrm{Fe}(\mathrm{III})$ to $\mathrm{Fe}(\mathrm{II})$ is proportional to the organic acid species concentrations. Since there are no organic acids in the model simulation, we used the organic carbon aerosol as the surrogate. In the model these aerosols are released from industrial activities as well as biomass burning. We again applied an e-folding timescale of 300 days from Hand et al. [2004]. The rate of conversion 

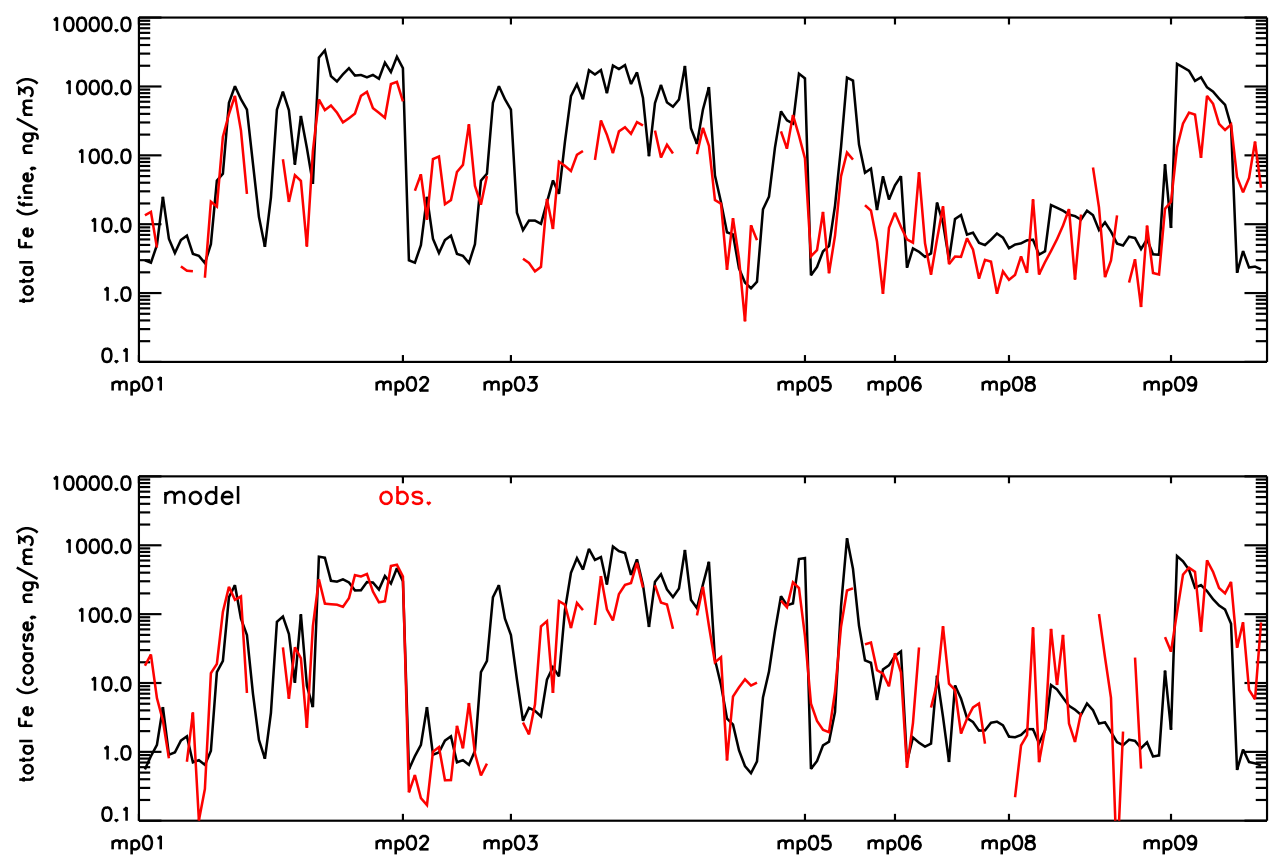

Figure 5. Total $\mathrm{Fe}$ concentration comparison between model results (black line) and observations (red line). The X-axis represents each observation taken as part of the cruises shown in Figure 4, similar to Figure 3.

from insoluble to soluble iron by organic acids $\left(\mathrm{K}_{\mathrm{org}}\right)$ was computed by equation (9):

$$
K_{\text {org }}(i, j)=\frac{C(i, j)}{C_{\text {avg }}} / \tau_{O B S}
$$

where $C(i, j)$ is the organic carbon concentration at each grid, and $\mathrm{C}_{\mathrm{avg}}$ is the global mean organic carbon concentration.

\subsubsection{Hematite Reaction Processing (HP)}

[25] Meskhidze et al. [2003] argue using an aerosol equilibrium box model that the acidity of the aerosol is critical to the conversion of $\mathrm{Fe}(\mathrm{III})$ to $\mathrm{Fe}(\mathrm{II})$, and that anthropogenic sulfate plays an important role in modulating acidity in the Pacific. In order to test their hypothesis in a global model, we simplify the reactions considerably, looking only at hematite in dust as a source of iron, and simplify
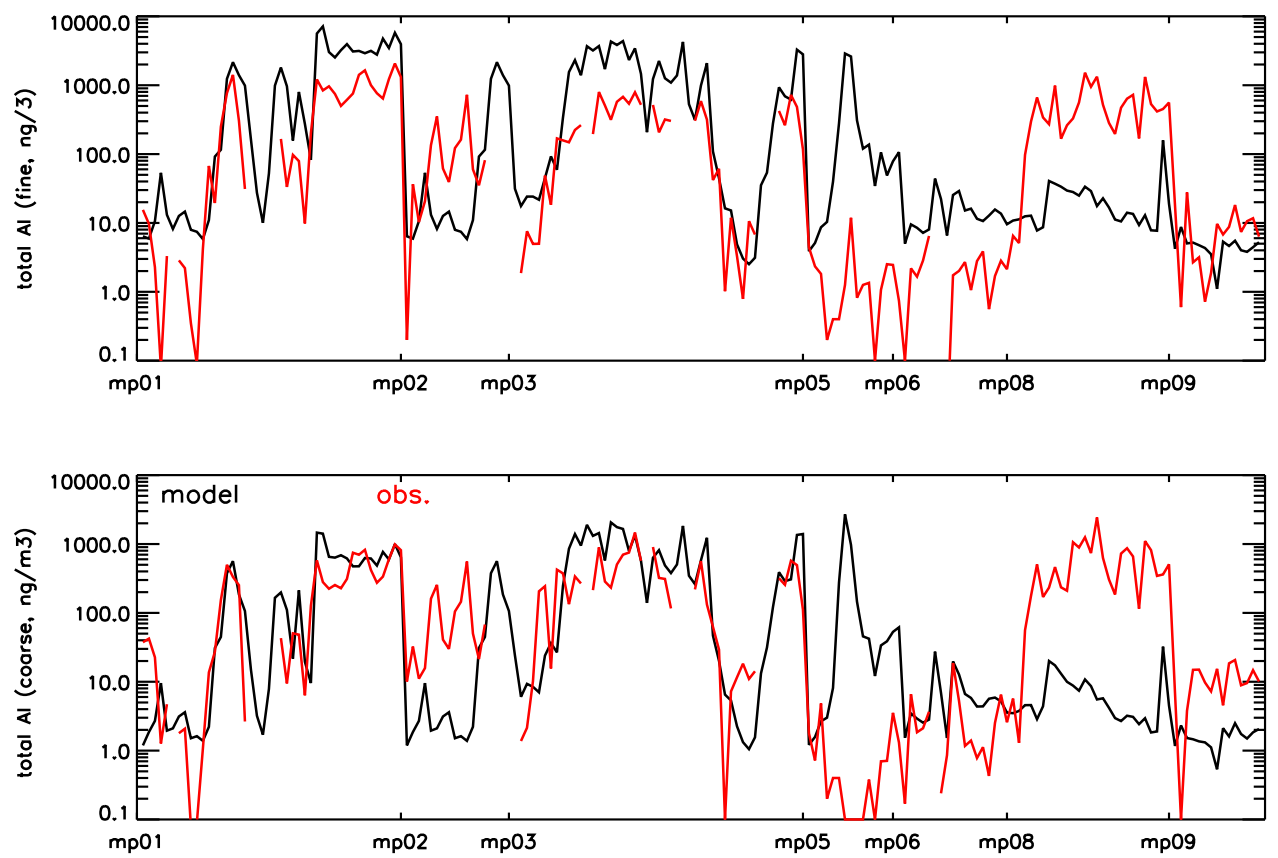

Figure 6. Total Al comparison between model results (black line) and observations (red line), similar to Figure 5. 

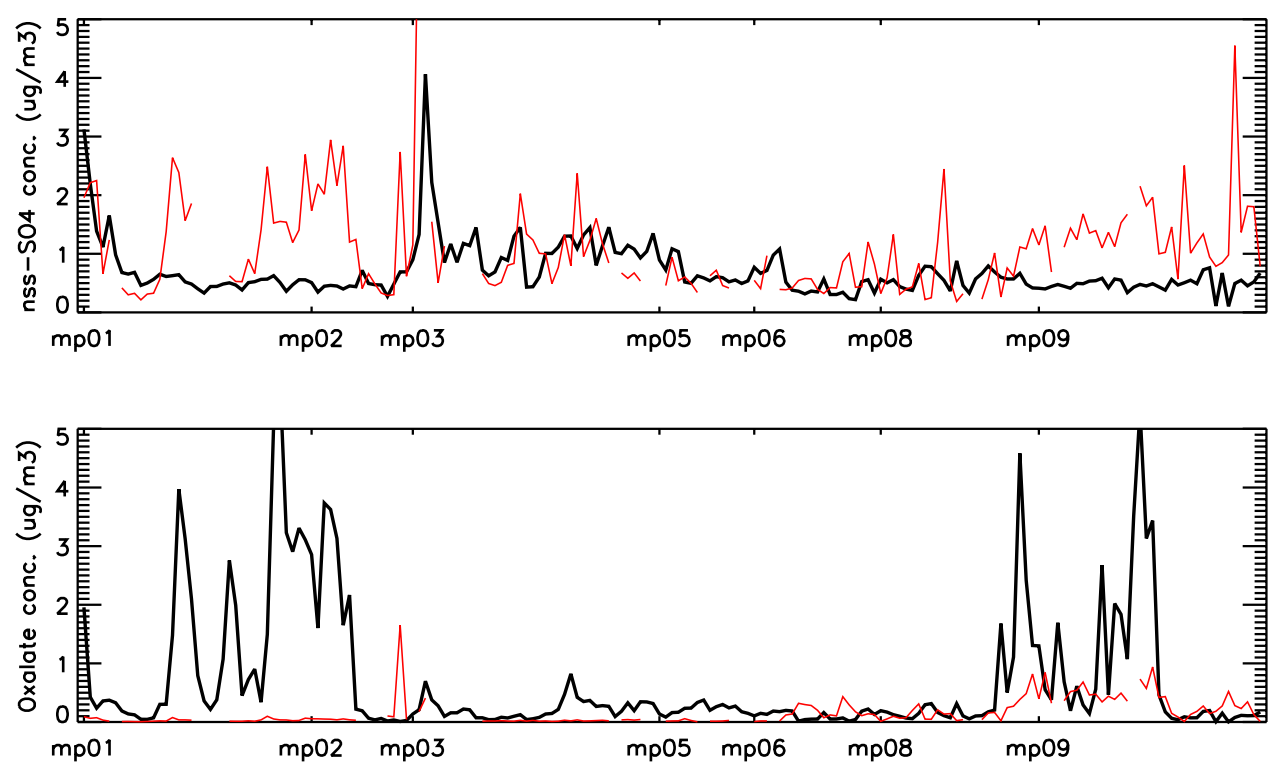

Figure 7. $\mathrm{SO}_{4}$ and oxalate comparisons between model results (black line) and observations (red line), similar to Figure 5.

our alkalinity calculation considerably. Following their hypothesis, we implement a mass balance equation for dissolved $\mathrm{Fe}$ (equation (10)):

$$
\frac{d[\mathrm{Fe}(I I)]}{d t}=W\left(\mathrm{Fe}_{\text {hem }}\right) \cdot R_{\text {hem }} \cdot[\text { dust }]
$$

where $[\mathrm{Fe}(\mathrm{II})]$ is the soluble concentration, [Dust] is the mass of the mineral aerosol $(\mathrm{g} / \mathrm{g}), \mathrm{WFe}_{\text {hem }}$ is the number of moles of Fe in a mole of hematite (2); and $\mathrm{R}_{\text {hem }}$ is the hematite dissolution rate (moles of dissolved hematite ( $\mathrm{g}$ of dust) ${ }^{-1}$ $\mathrm{s}^{-1}$ ). For, $\mathrm{R}_{\text {hem }}$, we adopt the formulation of Lasaga et al. [1994], similar to [Meskhidze et al., 2003] (equation (11)):

$$
R_{\text {hem }}=K_{r}(T) \cdot a\left(H^{+}\right)^{m} \cdot f\left(\Delta G_{r}\right) \mathrm{A}_{\text {hem }} \mathrm{W}_{\text {hem }}
$$

where $\mathrm{K}_{\mathrm{r}}$ is the temperature $(\mathrm{T})$ dependent reaction coefficient (moles dissolved $\mathrm{m}^{-2}$ of mineral $\left.\mathrm{s}^{-1}\right)$, a $\left(\mathrm{H}^{+}\right)$is the $\mathrm{H}^{+}$activity, $m$ is an empirical parameter, $f$ is a function of Gibbs free energy $\left(\Delta \mathrm{G}_{\mathrm{r}}\right)$, and accounts for the variation of the rate with deviation from equilibrium [Cama et al., 1999], $A_{i}$ is the specific surface area of mineral aerosols in units of $\mathrm{m}^{2} \mathrm{~g}^{-1}$, and $\mathrm{W}_{\mathrm{i}}$ is the weight fraction of the mineral in dust in units of $g$ of mineral ( $g$ of dust $)^{-1} \cdot f\left(\Delta G_{r}\right)=1$ was used in our simulation. Values for hematite are $\mathrm{m}=0.5 ; \mathrm{Ai}=100(\mathrm{~m} 2 / \mathrm{g})$; and $\mathrm{Wi}=5 \%$; while reaction coefficient $\mathrm{K}_{\mathrm{r}}$ depend on the total amount of the hematite already dissolved, following [Meskhidze et al., 2003; Azuma and Kametani, 1964; Blesa et al., 1994; Cornell and Schwertmann, 1996; Zinder et al., 1986; Skopp, 2000]:

Stage I ( 0 to $0.8 \%$ of total oxide dissolved)

$$
\mathrm{K}_{\mathrm{r}}=4.4 \times 10^{-12} \exp \left[9.2 \times 10^{3}(1 / 298-1 / \mathrm{T})\right]
$$

Stage II ( 0.8 to $40 \%$ of total oxide dissolved $)$

$$
\mathrm{K}_{\mathrm{r}}=1.8 \times 10^{-11} \exp \left[9.2 \times 10^{3}(1 / 298-1 / \mathrm{T})\right]
$$

Stage III (40 to $100 \%$ of total oxide dissolved)

$$
\mathrm{K}_{\mathrm{r}}=3.5 \times 10^{-12} \exp \left[9.2 \times 10^{3}(1 / 298-1 / \mathrm{T})\right]
$$

[26] For the $\mathrm{pH}$ value calculation, we simply set $\mathrm{pH}=7.5$ when concentration of $\mathrm{Ca}$ is larger than the concentration of $\mathrm{SO}_{4}$ concentration, and $\mathrm{pH}=2$ when concentration of $\mathrm{SO}_{4}$ is larger than the concentration of $\mathrm{Ca}$, and assume that $6 \%$ of dust is soluble Ca. $\mathrm{K}_{\mathrm{r}}$ was calculated depending on the amount of hematite dissolved and temperature.

\section{Results and Comparisons}

\subsection{Aerosol Model-Data Comparisons}

[27] The dust model used for the simulations here has been extensively compared to available observations for mean [Luo et al., 2003], interannual variability, and event behavior [Hand et al., 2004]. We use a slightly different wet deposition scheme than in previous simulations [Rasch et al., 2000], which impacts slightly our simulations, especially the seasonality over the Pacific Ocean. The model/data comparison shown in Figure 5 (and following figures) shows the observations and models as time series in time order. The cruise tracks shown in Figure 4 indicate where each cruise takes place, while Table 2 shows the time period for each cruise. Overall, the model does a good job in simulating the spatial and temporal variability of desert dust. Iron in mineral aerosols from the model and observations for the cruises is shown in Figure 5. Over 4 orders of magnitude the model does a good job of simulating the spatial and temporal variability, except for MP09. It is unclear why the model is unable to capture the MP09 cruise, perhaps due to errors in the sources of iron (either different dust sources, or and anthropogenic source of iron) or transport. The mean Fe concentration in the fine mode is 137 and $410 \mathrm{ng} \mathrm{m}^{-3}$, for the observations and model results, respectively; and in the coarse mode 112 and $130 \mathrm{ng} \mathrm{m}^{-3}$, for the observations and model results, respectively. As previously shown, the model over predicts the fine mode dust [Hand et al., 2004]. The correlation coefficient between the model and observations is 0.67 and 0.44 in the fine and coarse mode, respectively, suggesting that there are discrepancies in the simulation, but that the model on 

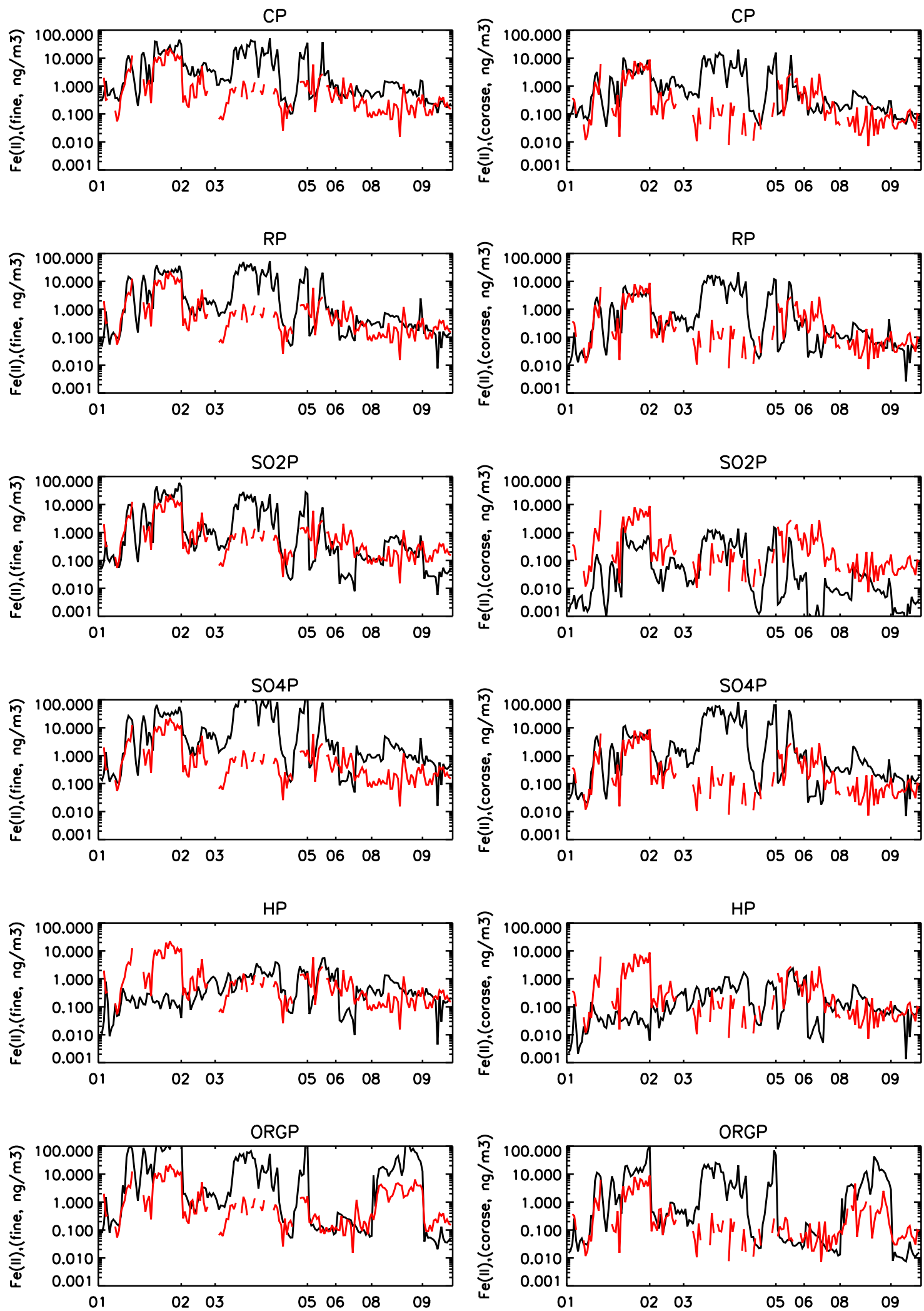

Figure 8. Soluble iron (Fe(II)) comparisons between model results (black line) and observations (red line), for each of the different processes described in the text. The number on $\mathrm{X}$-axis represents cruise number. 
Table 3. Correlation of Soluble Fe (Fe(II)) Between Model Simulation and Observation for All Cruises ${ }^{\mathrm{a}}$

\begin{tabular}{lcccccc}
\hline & Mean (f) & Std. Dev. (f) & $\mathrm{R}$ & Mean (c) & Std. Dev. (c) & $\mathrm{R}$ \\
\hline Obs & 1.95 & 3.52 & & 0.74 & 1.48 & \\
CP & 6.69 & 10.13 & $\mathbf{0 . 4 9}$ & 1.85 & 2.96 & $\mathbf{0 . 2 3}$ \\
RP & 7.47 & 11.35 & $\mathbf{0 . 4 6}$ & 2.06 & 3.46 & 0.13 \\
SO2P & 4.99 & 9.53 & $\mathbf{0 . 6 0}$ & 0.16 & 0.27 & $\mathbf{0 . 2 5}$ \\
SO4P & 19.16 & 33.89 & 0.19 & 5.88 & 12.04 & 0.0089 \\
HP & 0.71 & 0.88 & -0.094 & 0.23 & 0.34 & -0.035 \\
ORGP & 25.24 & 63.84 & $\mathbf{0 . 5 8}$ & 5.18 & 12.56 & $\mathbf{0 . 4 8}$ \\
\hline
\end{tabular}

${ }^{\mathrm{a}}$ Units are in $\mathrm{ng} \mathrm{m}^{-3}$. Values in bold are significant at $95 \%$.

the whole is capturing the spatial and temporal variability accurately.

[28] Figure 6 illustrates the comparison between observed $\mathrm{Al}$ and model calculated Al. Model Al was calculated by assuming $7.5 \%$ of dust mass. It can be seen that the model reproduces the $\mathrm{Al}$ for MP01, MP02, MP03, and overpredicts the observation for MP05, and under-predicts for MP08 and MP09. The fine mode Al concentrations are 273 and $776 \mathrm{ng} \mathrm{m}^{-3}$ for the observations and model simulation, respectively. The correlation coefficient between the model and observations for fine mode is 0.59 . The coarse mode mean $\mathrm{Al}$ concentrations are 227 and $246 \mathrm{ng} \mathrm{m}^{-3}$, for the observations and model simulation, respectively. The correlation coefficient for coarse mode between model and observations is 0.28 . It is unclear why the model tends to do a worse job simulating $\mathrm{Al}$ concentrations than total Fe. Overall the ratio of $\mathrm{Fe} / \mathrm{Al}$ is thought to be constant within a factor of 2 [Mahowald et al., 2005].

[29] Figure 7 shows nss- $\mathrm{SO}_{4}$ and oxalate comparisons between model simulations and observations of each cruise. Notice that we used organic carbon aerosol as substitute for oxalate in the model calculation. The overall correlation of nss- $\mathrm{SO}_{4}$ between model and observation are 0.22 , and are $0.11,0.33,0.42,-0.082,-0.029,0.55,-0.34$ for MP01, MP01, MP02, MP03, MP05, MP06, MP08, MP09 each cruise, respectively. These comparisons suggest less ability to simulate sulfate than desert dust for these cruises. The overall correlation of oxalate between observation and model is -0.047 . The model over-predicts oxalate for MP01, MP02, MP03, and MP09 and the over-prediction in the Atlantic during MP01 and Pacific during MP09 are very large. This suggests that our assumption that organic carbon aerosols can be a proxy for oxalate is not good; we include the case for completeness, but this implies our simulation will be biased.

\subsection{Soluble Iron and Iron Solubility Comparison}

[30] Modeled Fe(II) compared with observations is shown in Figure 8. Much of the 3 order of magnitude differences in $\mathrm{Fe}$ (II) is captured, similar to that of total Fe. Correlation coefficient for each process is shown in Table 3, suggesting that most of the different atmospheric processing mechanisms result in simulations that have statistically significant correlations with the observations, with the exception of $\mathrm{SO}_{4} \mathrm{P}$ and $\mathrm{HP}$. The model simulations tend to do better in the fine than the coarse mode.

[31] Figure 9 compares the modeled and observed iron solubility at specific points along the cruise track. The overall mean and correlation coefficients for the cruise tracks are shown in Table 4. In terms of the overall average iron solubility $(\mathrm{Fe}(\mathrm{II}) / \mathrm{Fe} * 100)$, the organic acid processing (ORGP) or radiative processing (RP) cases seem to do the best. But the correlation coefficients are only statistically significant for the cloud processing (CP) and the sulfur dioxide processing $\left(\mathrm{SO}_{2} \mathrm{P}\right)$ cases, and these correlations are low (0.20-0.24). Again, the model seems to capture the processing of fine particles better than coarse particles, which may be due to differences in conversion rate between fine and coarse particles, due either to differences in the surface area/volume ratios, or due to differences in chemical or mineralogical composition of different sized particles. Note that the statistically significant negative correlations, and the not statistically significant correlations between the model and observations suggest that the model is not able to capture the soluble iron processes well in these regions. Tables 5 and 6 show the mean solubility and correlations in solubility for each of the cruises and processes. It can be seen that no one processing can reproduce iron solubility well for all cruises. For the Atlantic, the CP or ORGP cases do the best capturing the overall average, but note that in the Atlantic, the model is over-predicting organic acids by a large margin (Figure 7), implying that this correspondence between model and observations is not for the right reasons. In the Pacific, the RP or HP cases do the best in predicting the overall average solubility iron. Table 6 shows that the $\mathrm{CP}$ and $\mathrm{SO}_{2} \mathrm{P}$ processing tend to do better than other cases if we look at correlation coefficients. The overall correlations for cloud processing and $\mathrm{SO}_{2}$ processing are around 0.19 0.24 for fine mode and $0.13-0.22$ for the coarse mode. Table 6 shows that overall correlations are better in Atlantic than in Pacific especially for cloud process and $\mathrm{SO}_{2}$ process. There is no single process that works best in both basins for all metrics.

[32] Above we study the single processing of iron conversion, but the conversion of iron could be due to multiple processes. Here we explore some combinations of processes for MP01-MP08. We simply allow both processes to occur at the same time using the equations described in section 3 , but do not link the processes. We tested $\mathrm{SO}_{2} \mathrm{P}+\mathrm{RP}, \mathrm{RP}+$ $\mathrm{HP}, \mathrm{SO}_{2} \mathrm{P}+\mathrm{HP}, \mathrm{SO}_{2} \mathrm{P}+\mathrm{CP}$ and $\mathrm{CP}+\mathrm{HP}$, because analyses show $\mathrm{SO}_{2} \mathrm{P}, \mathrm{RP}, \mathrm{HP}$, and $\mathrm{CP}$ each single process has a relative higher correlation between model and observation comparing with other processes. Figure 10 and Table 7 show the daily iron solubility and correlations between model simulation and observations for the mixed processes. It can be seen that the correlations of coupled $\mathrm{SO}_{2} \mathrm{P}+\mathrm{CP}$, and $\mathrm{CP}+\mathrm{HP}$ are higher than other processes. This is consistent with cloud processing and acidity playing a role 

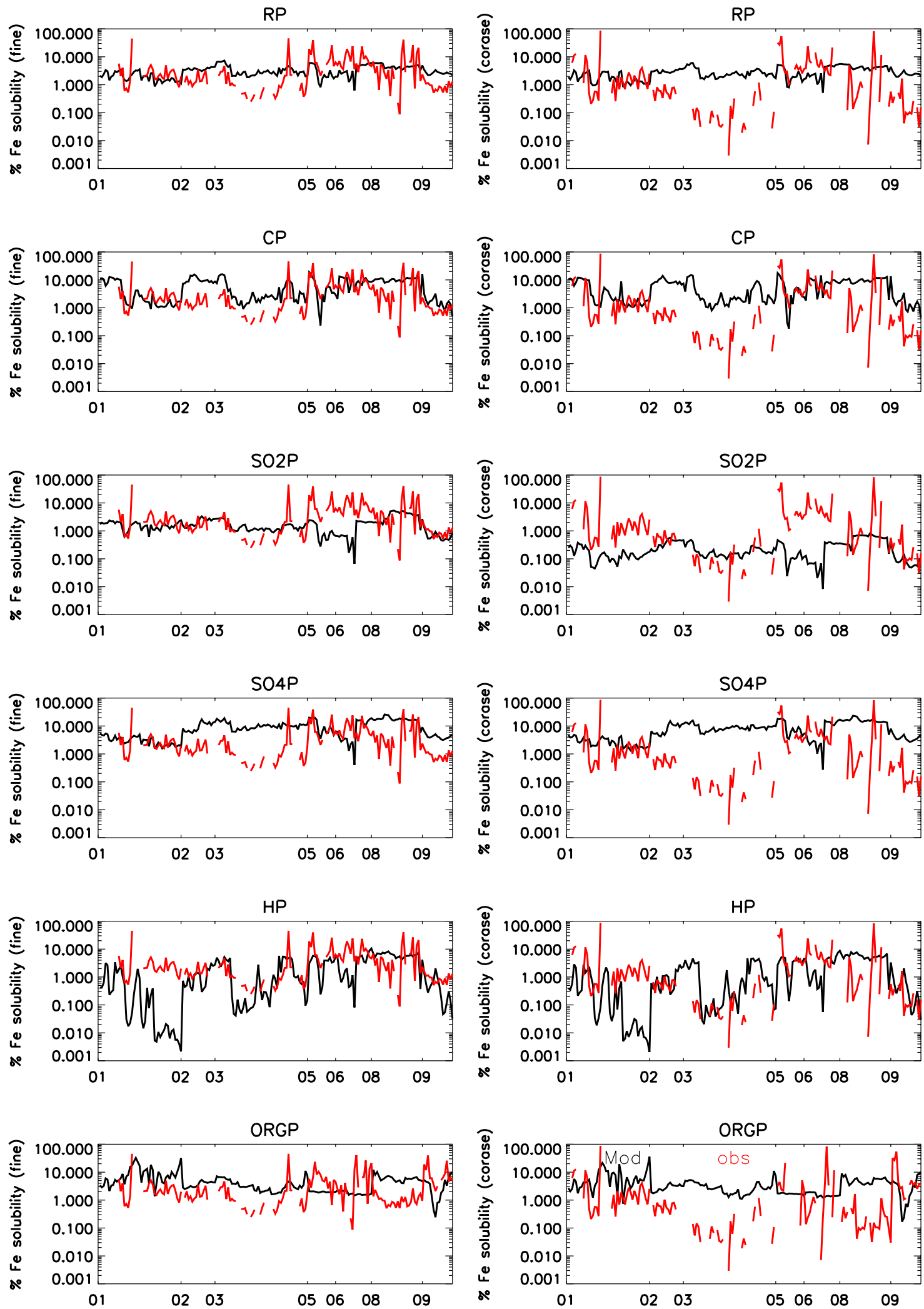

Figure 9. Percent iron solubility (Fe(II)/Fe * 100) comparisons between model results (black line) and observations (red line), for each of the different processes described in the text. The number on X-axis represents cruise number. 
Table 4. Correlation of Iron Solubility (\%) Between Model Results and Observed Concentrations for All Cruises ${ }^{\mathrm{a}}$

\begin{tabular}{lcccccc}
\hline Case & Mean (Fine) & Std. Dev. (Fine) & R (Fine) & Mean (Coarse) & Std. Dev (Coarse) & R (Coarse) \\
\hline OBS & 5.08 & 8.44 & & 4.20 & 11.31 & \\
RP & 3.42 & 1.68 & 0.07 & 2.95 & 1.42 & 0.15 \\
CP & 6.34 & 4.79 & $\mathbf{0 . 2 4}$ & 5.67 & 0.38 & $\mathbf{0 . 2 2}$ \\
SO2P & 1.67 & 1.04 & $\mathbf{0 . 2 0}$ & 0.23 & 6.29 & 0.13 \\
SO4P & 9.88 & 6.88 & 0.03 & 8.48 & 2.84 & 0.11 \\
HP & 2.78 & 3.15 & 0.09 & 2.37 & 3.82 & 0.10 \\
ORGP & 4.57 & 3.79 & -0.01 & 3.86 & & 0.09 \\
\hline
\end{tabular}

${ }^{\mathrm{a}}$ Values in bold are significant at $95 \%$.

in the processing of atmospheric iron. It can be seen that mean solubility and correlations are better for mixed processes than single process, even though we have not tuned our coefficients in any way. Table 8 shows the iron solubility for mixed processes for each cruise and compared with observations. It can be seen that for the overall mean, the $\mathrm{SO}_{2} \mathrm{P}+\mathrm{RP}$ and $\mathrm{RP}+\mathrm{HP}$ cases are better than other mixed processes. The $\mathrm{SO}_{2} \mathrm{P}+\mathrm{HP}$ case under-predicts iron solubility and $\mathrm{SO}_{2} \mathrm{P}+\mathrm{CP}$ and $\mathrm{CP}+\mathrm{HP}$ cases over-predict iron solubility.

[33] In order to compare the importance of different processes in different regions and different seasons, the normalized iron solubility were calculated. The normalized iron solubility was defined as the regionally and seasonally averaged ocean iron solubility divided by global annually averaged ocean iron solubility (Figure 11). Nine ocean regions, North Pacific $\left(10^{\circ} \mathrm{N}-40^{\circ} \mathrm{N}, 155^{\circ} \mathrm{E}-180^{\circ} \mathrm{E}\right.$, $\left.140^{\circ} \mathrm{W}-180^{\circ} \mathrm{W}\right)$, South Pacific $\left(40^{\circ} \mathrm{S}-10^{\circ} \mathrm{S}, 155^{\circ} \mathrm{E}-\right.$ $\left.180^{\circ} \mathrm{E}, 140^{\circ} \mathrm{W}-180^{\circ} \mathrm{W}\right)$, Equatorial East Pacific $\left(10^{\circ} \mathrm{S}-\right.$ $\left.10^{\circ} \mathrm{N}, 80^{\circ} \mathrm{W}-155^{\circ} \mathrm{W}\right)$, North Atlantic $\left(10^{\circ} \mathrm{N}-40^{\circ} \mathrm{N}\right.$, $\left.10^{\circ} \mathrm{W}-60^{\circ} \mathrm{W}\right)$, South Pacific $\left(40^{\circ} \mathrm{S}-10^{\circ} \mathrm{S}, 10^{\circ} \mathrm{W}-60^{\circ} \mathrm{W}\right)$, Caribbean Sea $\left(10^{\circ} \mathrm{N}-20^{\circ} \mathrm{N}, 60^{\circ} \mathrm{W}-90^{\circ} \mathrm{W}\right)$, Arabian Sea $\left(0^{\circ}-20^{\circ} \mathrm{N}, 50^{\circ} \mathrm{E}-70^{\circ} \mathrm{E}\right)$, Indian Ocean $\left(30^{\circ} \mathrm{S}-20^{\circ} \mathrm{N}, 60^{\circ} \mathrm{E}-\right.$ $\left.100^{\circ} \mathrm{E}\right)$, and South Ocean $\left(70^{\circ} \mathrm{S}-55^{\circ} \mathrm{S}, 0^{\circ}-180^{\circ} \mathrm{E}, 0^{\circ}-\right.$ $180^{\circ} \mathrm{W}$ ), were calculated. Because the reaction rates given in section 3.2 are very uncertain, but perhaps the processes are correct, we can use these normalized solubilities to examine when and where each process is most effective. It can be seen from Figure 11 that the normalized iron solubility is higher in Pacific (North Pacific, South Pacific, and Equatorial East Pacific) than in other ocean regions for all processes. Cloud processing is the most able to process iron in the Southern Ocean. There are seasonal differences in the different processes, such as a higher $\mathrm{HP}$ or $\mathrm{SO}_{4} \mathrm{P}$ conversion rate during the summer time in the North Pacific than other seasons. The highest season for conversion of iron solubility in the Arabian Sea is the fall for the $\mathrm{SO}_{2} \mathrm{P}$, $\mathrm{SO}_{4} \mathrm{P}$ and HP processes. The differences obviously have to do with higher relative reaction rates for the processes. For example, there are more clouds in the North Pacific than North Atlantic downwind of the dust sources, since for the North Pacific, the dust is being transported in the storm track, but farther south in the subtropics for the North Atlantic deposited dust.

\subsection{Global Implications}

[34] Annual averaged global surface maps of iron solubility for 6 processes are shown in Figure 12. Figure 12 illustrates that the lowest values of iron solubility occur close to source regions, consistent with low solubility of crustal sources. The fine mode percent solubility is higher than the coarse mode globally except near source regions where it is roughly the same, due to the shorter lifetimes of larger particles (since we have no size segregated differences in processes). This means that the observation of higher solubility in fine mode aerosols than coarse mode aerosols could be simply explained by the longer lifetime [Hand et al., 2004]. There is higher solubility in the Northern Hemisphere than the Southern Hemisphere in cases $\mathrm{SO}_{2} \mathrm{P}, \mathrm{SO}_{4} \mathrm{P}$ and $\mathrm{ORGP}$, consistent with the large gradients in emissions of anthropogenic compounds these processes rely on. Solubilities in the cases of RP, and HP tend to be highest in the tropical Pacific Ocean, and smaller close to source regions and increase slightly as you move to the high latitudes. For the $\mathrm{CP}$ case, the solubilities are smallest close to the source regions, and increase as one moves to higher latitudes. We have only two cruises which extends from the high to low latitudes in both the Northern

Table 5. Iron Solubility (\%) Comparison for Each Cruise and Each Process

\begin{tabular}{|c|c|c|c|c|c|c|c|c|c|c|c|c|c|c|}
\hline \multirow[b]{2}{*}{ Cruise } & \multicolumn{2}{|c|}{ Obs } & \multicolumn{2}{|c|}{$\mathrm{CP}$} & \multicolumn{2}{|c|}{$\mathrm{RP}$} & \multicolumn{2}{|c|}{$\mathrm{SO} 2 \mathrm{P}$} & \multicolumn{2}{|c|}{ SO4P } & \multicolumn{2}{|c|}{ HP } & \multicolumn{2}{|c|}{ ORG } \\
\hline & Fine & Coarse & Fine & Coarse & Fine & Coarse & Fine & & Fine & Coarse & Fine & Coarse & Fine & Coarse \\
\hline Atlantic & 5.84 & 4.44 & 5.28 & 4.59 & 2.81 & 2.38 & 1.43 & 0.18 & 7.51 & 6.46 & 1.81 & 1.50 & 5.57 & 4.57 \\
\hline MP01 & 6.62 & 5.08 & 3.11 & 3.37 & 1.84 & 1.69 & 1.50 & 0.14 & 2.78 & 2.49 & 0.44 & 0.52 & 8.90 & 7.02 \\
\hline MP03 & 2.38 & 0.17 & 4.79 & 3.46 & 3.40 & 2.72 & 1.51 & 0.19 & 10.56 & 8.78 & 1.91 & 1.31 & 3.87 & 3.08 \\
\hline MP08 & 4.19 & 2.73 & 5.64 & 4.94 & 3.26 & 2.76 & 1.82 & 0.24 & 9.16 & 7.58 & 2.19 & 1.70 & 6.18 & 5.24 \\
\hline Pacific & 4.32 & 3.94 & 10.35 & 9.56 & 4.94 & 4.26 & 2.44 & 0.41 & 16.15 & 14.56 & 5.53 & 4.93 & 2.48 & 2.01 \\
\hline MP02 & 1.66 & 0.50 & 10.56 & 9.11 & 3.67 & 3.06 & 2.09 & 0.37 & 9.68 & 8.11 & 1.13 & 0.98 & 3.69 & 2.85 \\
\hline MP06 & 8.49 & 7.57 & 10.22 & 9.88 & 4.30 & 4.06 & 4.17 & 0.66 & 18.21 & 16.72 & 6.19 & 5.67 & 1.79 & 1.59 \\
\hline MP09 & 0.53 & 3.08 & 11.10 & 10.39 & 6.30 & 5.03 & 1.49 & 0.27 & 20.49 & 18.37 & 8.64 & 7.80 & 2.47 & 1.91 \\
\hline$A v g$ & 5.08 & 4.20 & 7.80 & 7.08 & 3.84 & 3.32 & 1.94 & 0.29 & 11.87 & 10.51 & 3.67 & 3.22 & 4.03 & 3.29 \\
\hline
\end{tabular}


Table 6. Correlation of Iron Solubility for Each Cruise Between Observations and Model Simulations ${ }^{\mathrm{a}}$

\begin{tabular}{|c|c|c|c|c|c|c|c|c|c|c|c|c|}
\hline \multirow[b]{2}{*}{ Cruise } & \multicolumn{2}{|c|}{$\mathrm{CP}$} & \multicolumn{2}{|c|}{$\mathrm{RP}$} & \multicolumn{2}{|c|}{$\mathrm{SO} 2 \mathrm{P}$} & \multicolumn{2}{|c|}{ SO4P } & \multicolumn{2}{|c|}{ HP } & \multicolumn{2}{|c|}{ ORGP } \\
\hline & Fine & Coarse & Fine & Coarse & Fine & Coarse & Fine & Coarse & Fine & Coarse & Fine & Coarse \\
\hline Atlantic & 0.33 & 0.19 & 0.16 & 0.12 & 0.28 & 0.17 & 0.11 & 0.09 & 0.19 & 0.09 & 0.03 & 0.21 \\
\hline MP01 & 0.41 & 0.037 & 0.42 & 0.22 & 0.29 & 0.11 & 0.63 & 0.31 & 0.28 & 0.03 & -0.04 & 0.20 \\
\hline MP03 & 0.31 & 0.66 & 0.24 & 0.48 & 0.16 & 0.59 & 0.09 & 0.22 & 0.31 & 0.50 & 0.13 & 0.25 \\
\hline MP08 & 0.25 & 0.11 & 0.15 & 0.09 & 0.26 & 0.12 & 0.11 & 0.052 & 0.21 & 0.10 & 0.26 & 0.15 \\
\hline Pacific & 0.03 & 0.32 & -0.08 & 0.19 & -0.04 & 0.05 & -0.12 & 0.14 & -0.12 & 0.04 & -0.29 & 0.17 \\
\hline MP02 & -0.23 & -0.019 & -0.10 & 0.049 & 0.24 & -0.063 & 0.21 & 0.22 & -0.06 & 0.095 & 0.17 & -0.068 \\
\hline MP05 & -0.44 & 0.26 & -0.25 & -0.22 & 0.22 & 0.11 & -0.39 & -0.77 & -0.22 & -0.47 & 0.08 & 0.1 \\
\hline MP06 & 0.17 & 0.25 & -0.07 & 0.048 & 0.11 & -0.06 & -0.26 & -0.13 & -0.31 & -0.18 & -0.46 & -0.26 \\
\hline MP09 & 0.44 & 0.18 & -0.59 & 0.18 & -0.02 & -0.04 & -0.58 & 0.13 & -0.65 & 0.09 & 0.59 & -0.09 \\
\hline Overall & 0.24 & 0.22 & 0.072 & 0.15 & 0.19 & 0.13 & 0.033 & 0.11 & 0.089 & 0.098 & -0.01 & 0.093 \\
\hline
\end{tabular}

${ }^{a}$ Values in bold are significant at $95 \%$.

and Southern Hemisphere and measured labile iron (the JCR and Polarstern cruises shown in Figures 1c and 1d), and these cruises show roughly symmetric solubilities about the equator, more consistent with $\mathrm{CP}$. Note that we are assuming here that all the iron comes from dust particlessoluble iron may come from industrial processes as well. However, one would assume that anthropogenic soluble iron would be proportional to anthropogenic emissions of other compounds (sulfur dioxide, fossil fuel carbon dioxide) and thus would be larger in the Northern Hemisphere than the Southern Hemisphere. This is not seen in the limited observational data.

[35] Spatial distributions of mixed processes are shown in the Figure 13. Whether the north-south gradient typical of $\mathrm{SO}_{2} \mathrm{P}, \mathrm{SO}_{4} \mathrm{P}$ or ORGP cases dominates or the symmetric solubilities of RP, CP or HP dominates depends on the relative reaction rates used, which are not well known. If both $\mathrm{SO}_{2} \mathrm{P}$ and $\mathrm{CP}$ are operating, for example, we can have a simulation of solubilities that is symmetric about the equator, consistent with the limited observations we have.

[36] Finally we look at the relationships between sulfate and organic aerosols and iron solubility in the model in these different cases. In section 2 we examined these relationships in the observations, and obtain no statistically significant result. Here we can test the case where if indeed the sulfur or organic aerosols are important for processes in the model, how will that show up in the observations. This is shown in Table 9. Significant positive correlation for $\mathrm{SO}_{2} \mathrm{P}$ and $\mathrm{SO}_{4} \mathrm{P}$ processes in MP02 and MP09 could show that these two processes play the role in iron soluble conversion in these cruises. But there are significant negative correlations for some processes in different basins at different circumstances. Although the correlation can be high for individual cruises, overall there is a lack of statistically significant correlation between sulfate and solubility, even in the cases where sulfur is the important in the process converting the iron $\left(\mathrm{SO}_{2} \mathrm{P}\right.$ or $\mathrm{SO}_{4} \mathrm{P}$ or HP). Similarly there is no correlation between the organic acid and the solubility in the case where organic acids are in the model doing the processing of iron solubility. This is because the sulfur or organic acids are highest close to the source areas, while the iron processed by the compounds is highest downwind, which can result in negative or no correlations between solubility and sulfur concentrations. Thus this nonintuitive result appears consistent with the observations discussed in section 2, and correlations in observations are not likely to provide us with information about what constituents are doing the processing, unfortunately.

\subsection{Soluble Iron Deposition Estimation}

[37] The bioavailability of iron is very important to the biogeochemistry cycle in the ocean. Here we estimate the amount of soluble iron deposited in the global open ocean by using the averaged model calculated global iron solubility from this study, and a long term average of dust deposition from a 22-year model simulation [Luo et al., 2003; Mahowald et al., 2003]. Figure 14 illustrates open ocean soluble iron distribution for 6 processes. The largest amounts of iron are deposited into the tropical Atlantic, Indian Ocean and North Pacific for all processes. We calculated total soluble iron to the open ocean for 6 processes. The deposited soluble iron in North Atlantic $\left(10^{\circ} \mathrm{W}-60^{\circ} \mathrm{W}, 0^{\circ}-55^{\circ} \mathrm{N}\right)$, South Atlantic $\left(10^{\circ} \mathrm{W}-60^{\circ} \mathrm{W}, 0-\right.$ $\left.55^{\circ} \mathrm{S}\right)$, Indian Ocean $\left(60^{\circ} \mathrm{E}-100^{\circ} \mathrm{E}, 30^{\circ} \mathrm{S}-25^{\circ} \mathrm{N}\right)$, North Pacific $\left(125^{\circ} \mathrm{E}-130^{\circ} \mathrm{W}, 0^{\circ}-55^{\circ} \mathrm{N}\right)$ and South Pacific $\left(125^{\circ} \mathrm{E}-130^{\circ} \mathrm{W}, 0^{\circ}-55^{\circ} \mathrm{S}\right)$, Antarctic $\left(0^{\circ}-180^{\circ} \mathrm{E}, 0^{\circ}-\right.$ $\left.180^{\circ} \mathrm{W}, 60^{\circ} \mathrm{S}-90^{\circ} \mathrm{S}\right)$ and Arctic $\left(0^{\circ}-180^{\circ} \mathrm{E}, 0-180^{\circ} \mathrm{W}\right.$, $60^{\circ} \mathrm{N}-90^{\circ} \mathrm{N}$ ) are shown in Table 10 . The magnitudes range from $3.59 \times 10^{8}$ to $1.63 \times 10^{9} \mathrm{~kg}$ soluble iron per year $(\mathrm{see}$ Table 10). An average estimate of soluble iron in the global open ocean from all the cases considered here is $\sim 8.760 \times$ $10^{8} \mathrm{~kg} \mathrm{yr}^{-1}$.

\section{Summary and Conclusion}

[38] Analysis of available soluble iron data suggest that iron solubilities vary greatly spatially and temporally, with no consistent trends between the Pacific and the Atlantic. Limited iron measurements in the Pacific and Atlantic oceans suggest that Pacific Ocean iron solubilities should be larger [e.g., Boyle et al., 2005], leaving a discrepancy between iron observed in the oceans and iron being deposited to the surface oceans. Fine mode desert dust particles are observed to have twice the solubilities of coarse mode desert dust particles $(1.95 \%$ vs. $0.74 \%)$. This appears to be largely due to the difference in the lifetime of fine and coarse particles, based on the modeling conducted here. Observations show larger solubilities farther from the source areas, in general, and a solubility distribution that is symmetric around the equator. If iron solubility is defined 

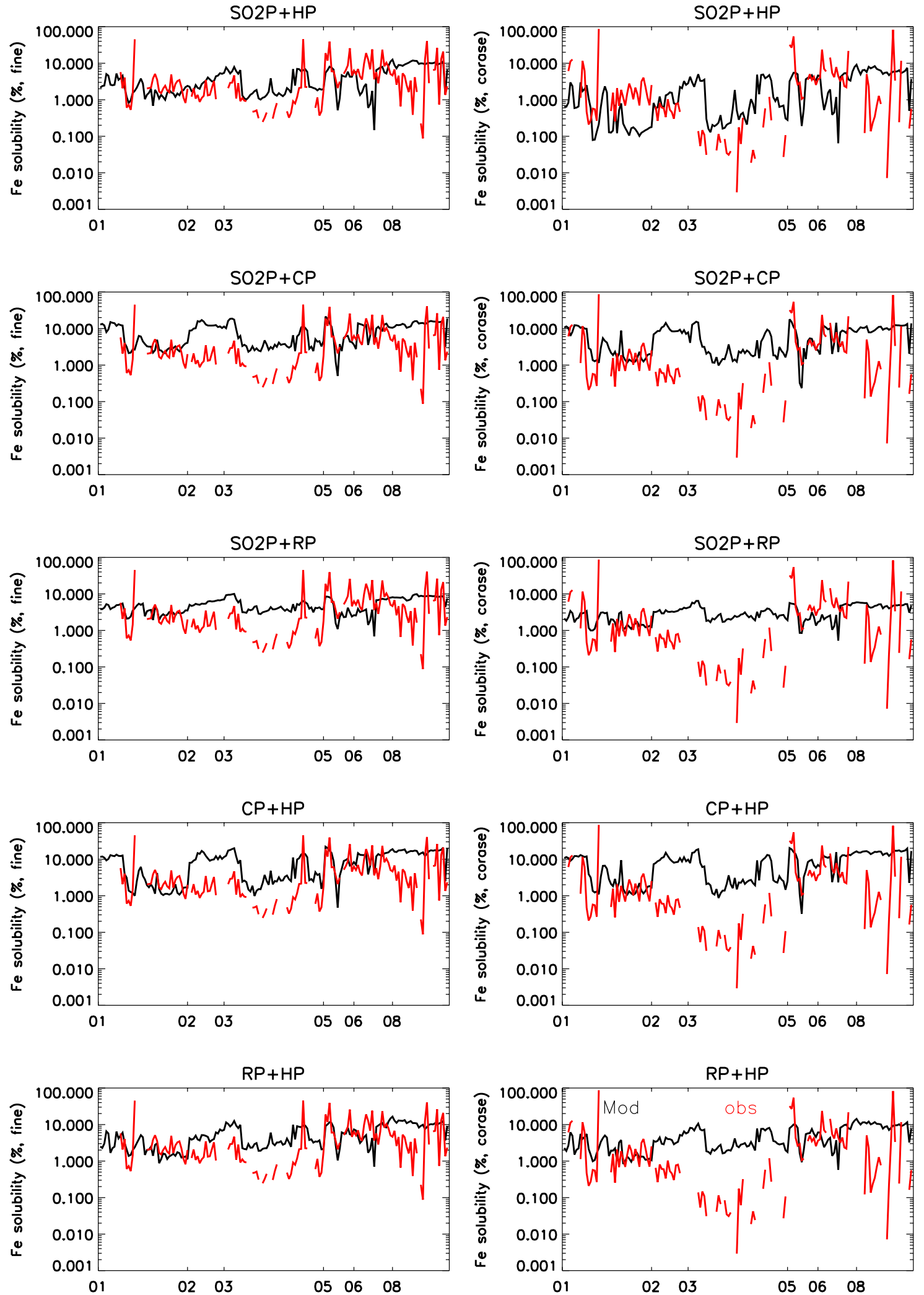

Figure 10. Percent iron solubility (Fe(II)/Fe * 100) comparisons between model results (black line) and observations (red line), for each of the different 'combined' processes described in the text. The number on $\mathrm{X}$-axis represents cruise number. 
Table 7. Correlation of Iron Solubility of Mix-Processes Between Observation and Model Simulation From MP01-MP08 ${ }^{\mathrm{a}}$

\begin{tabular}{|c|c|c|c|c|c|c|}
\hline & Mean (f) & Std Dev (f) & $\mathrm{R}$ & Mean (c) & Std Dev (c) & $\mathrm{R}$ \\
\hline Obs & 5.04 & 8.72 & & 3.80 & 11.41 & \\
\hline $\mathrm{SO} 2 \mathrm{P}+\mathrm{HP}$ & 3.95 & 3.28 & 0.24 & 2.05 & 2.27 & 0.15 \\
\hline $\mathrm{SO} 2 \mathrm{P}+\mathrm{CP}$ & 7.61 & 5.36 & 0.30 & 5.43 & 4.38 & 0.24 \\
\hline $\mathrm{SO} 2 \mathrm{P}+\mathrm{RP}$ & 4.87 & 2.24 & 0.20 & 2.93 & 1.35 & 0.18 \\
\hline $\mathrm{CP}+\mathrm{HP}$ & 8.18 & 6.47 & 0.31 & 7.02 & 5.77 & 0.23 \\
\hline RP+HP & 5.45 & 3.76 & 0.22 & 4.53 & 3.16 & 0.17 \\
\hline $\mathrm{CP}$ & 6.45 & 4.59 & 0.25 & 5.97 & 4.26 & 0.21 \\
\hline RP & 3.24 & 1.47 & 0.15 & 2.83 & 1.31 & 0.16 \\
\hline $\mathrm{SO} 2 \mathrm{P}$ & 1.84 & 1.07 & 0.13 & 0.26 & 0.18 & 0.10 \\
\hline HP & 2.38 & 2.52 & 0.18 & 2.12 & 2.25 & 0.11 \\
\hline
\end{tabular}

${ }^{\mathrm{a}}$ Statistics for single process cruises over MP01-MP08 are shown for comparison. Values in bold are significant at $95 \%$.

as the labile iron fraction, it is roughly twice as large as the iron(II) fraction. Here we consider the iron(II) fraction as soluble, and thus bioavailable, but more information from oceanographers on the bioavailable fraction is required for a more definitive answer on the availability of iron being deposited in desert dust.

[39] Several different processes for conversion of Fe(III) to $\mathrm{Fe}$ (II) are simulated in a model, including 3 different sulfur based approaches, and one approach based on conversion by organic acids. This last case will suffer from a poor simulation of the organic acids thought to be important for conversion of $\mathrm{Fe}$ (III) to $\mathrm{Fe}(\mathrm{II})$. We include very simple assumptions about the conversion rates for iron, which will result in large uncertainties in our model results. We include detailed statistical analysis of the match between these different cases and the cruises considered here, which tend to show different processes do better in different basins. Overall the model calculated correlations $\mathrm{SO}_{2} \mathrm{P}$ and cloud process tend to do a better job than other cases, and combination processes, such as $\mathrm{SO}_{2} \mathrm{P}$ and $\mathrm{CP}$ (cloud processing) are even better. This is consistent with our understanding that sulfur processing of dust probably occurs in clouds. The large scale picture of iron solubility shown in Figure 1 from the observations provides important information about the relevant processes. Cases in which only sulfur or anthropogenic organic acids are allowed to convert the iron tended to result in distributions of iron solubility with much larger solublities in the North Hemisphere than the Southern Hemisphere, which is inconsistent with the two cruises with data in the Southern Hemisphere we consider here [Baker, 2004]. The data from Baker [2004] suggest solubilities are symmetric around the equator, more similar to cases in which cloud processing is important, either alone or with other processes. This suggests that in much of the atmosphere, cloud droplets may be acidic enough to process the iron, and that prediction of cloud processing is more important than prediction of acidity distributions. This is in contrast to the hypotheses of increased pollution driving higher solubilities of other studies [Meskhidze et al., 2003, 2005]. We note that this apparent symmetry is probably governed by the fact that these cruises sampled low-solubility, near-source Saharam dust near the equator, and thus low solubility may not be a characteristic of equatorial regions per se. Comparisons show that the areas with the largest differences in the simulations are in the Southern Atlantic or Southern Pacific oceans. More observations in these areas will help us identify the most likely scenarios. All processes simulated in this study show higher solubilities in the Pacific than Atlantic Ocean, without including the effects of pollution, suggesting that pollution may not play an important role in the observed higher concentrations of iron in the Pacific than the Atlantic [e.g., Boyle et al., 2005].

[40] Correlations between observed sulfate or organic acids and iron solubility suggest no significant correlation.

Table 8. Iron Solubility (\%) Comparison for the Mixed Processes for MP01-MP08 Cruises

\begin{tabular}{|c|c|c|c|c|c|c|c|}
\hline & & $\mathrm{SO} 2 \mathrm{P}+\mathrm{HP}$ & $\mathrm{SO} 2 \mathrm{P}+\mathrm{CP}$ & $\mathrm{SO} 2 \mathrm{P}+\mathrm{RP}$ & $\mathrm{CP}+\mathrm{HP}$ & $\mathrm{RP}+\mathrm{HP}$ & OBS \\
\hline \multirow[t]{2}{*}{ Atlantic } & Fine & 4.22 & 7.66 & 5.14 & 7.93 & 5.42 & 4.40 \\
\hline & Coarse & 2.26 & 5.66 & 3.03 & 7.40 & 4.78 & 2.66 \\
\hline \multirow[t]{2}{*}{ MP01 } & Fine & 2.15 & 5.76 & 3.62 & 4.70 & 2.56 & 6.62 \\
\hline & Coarse & 0.72 & 4.49 & 1.94 & 4.90 & 2.35 & 5.08 \\
\hline \multirow[t]{2}{*}{ MP03 } & Fine & 3.12 & 5.65 & 4.74 & 5.88 & 4.97 & 2.38 \\
\hline & Coarse & 1.55 & 3.75 & 2.94 & 4.92 & 4.11 & 0.17 \\
\hline \multirow[t]{2}{*}{ MP08 } & Fine & 9.46 & 13.76 & 8.17 & 16.16 & 10.56 & 4.19 \\
\hline & Coarse & 5.95 & 10.41 & 4.83 & 15.28 & 9.69 & 2.73 \\
\hline \multirow[t]{2}{*}{ Pacific } & Fine & 4.29 & 10.08 & 5.02 & 11.30 & 6.24 & 5.58 \\
\hline & Coarse & 2.71 & 7.86 & 3.30 & 10.05 & 5.49 & 4.23 \\
\hline \multirow[t]{2}{*}{ MP02 } & Fine & 3.35 & 12.22 & 5.84 & 11.31 & 4.93 & 1.66 \\
\hline & Coarse & 1.42 & 9.10 & 3.48 & 9.78 & 4.16 & 0.50 \\
\hline \multirow[t]{2}{*}{ MP05 } & Fine & 4.78 & 7.24 & 4.15 & 9.74 & 6.64 & 6.60 \\
\hline & Coarse & 3.53 & 5.80 & 2.86 & 8.96 & 6.0 & 4.63 \\
\hline \multirow[t]{2}{*}{ MP06 } & Fine & 4.78 & 10.31 & 4.94 & 12.54 & 7.17 & 8.49 \\
\hline & Coarse & 3.26 & 8.32 & 3.49 & 11.17 & 6.35 & 7.57 \\
\hline \multirow[t]{2}{*}{ Overall } & Fine & 3.98 & 7.81 & 4.94 & 8.31 & 5.43 & 4.99 \\
\hline & Coarse & 2.23 & 5.86 & 3.04 & 7.61 & 4.97 & 4.20 \\
\hline
\end{tabular}



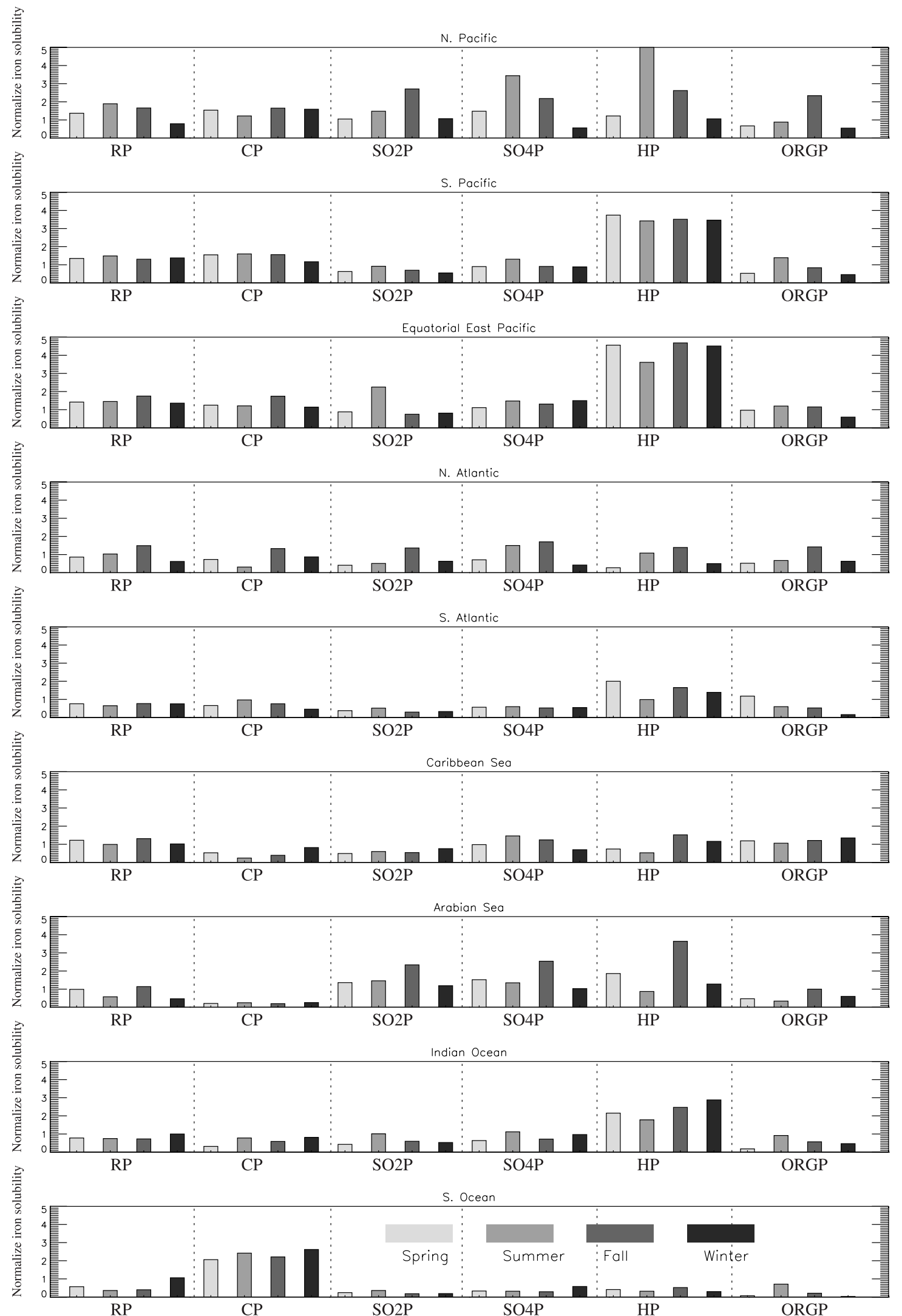

Figure 11. Bar graph showing the normalized iron solubility for different processes in different regions and seasons. The values represent the average $\mathrm{Fe}(\mathrm{II})$ deposited in the regions defined in the text, normalized by the globally and annually average amount of $\mathrm{Fe}(\mathrm{II})$ deposited. Thus these values show the relative importance of different mechanisms, if they had the same globally and annually averaged conversion rate to soluble iron. 

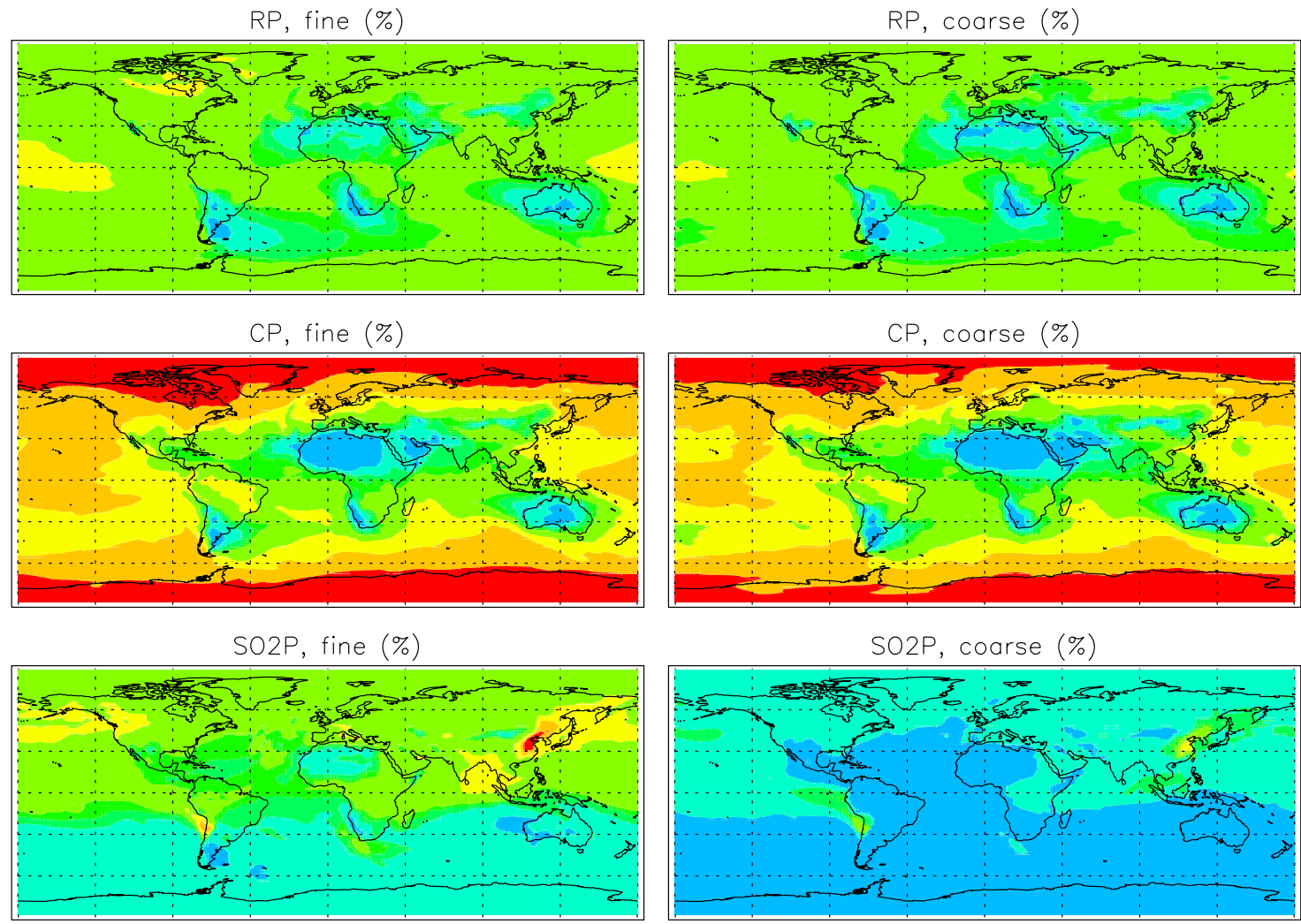

SO4P, fine (\%)

SO4P, coarse (\%)
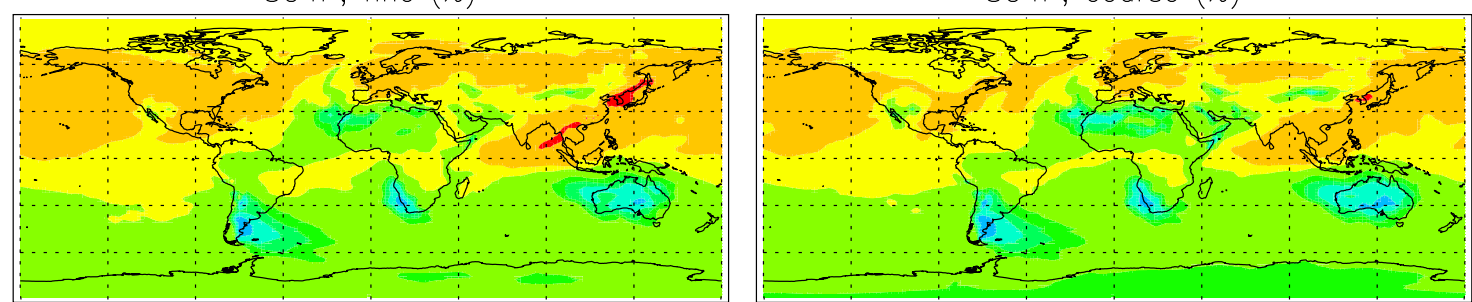

$\mathrm{HP}$, fine (\%)

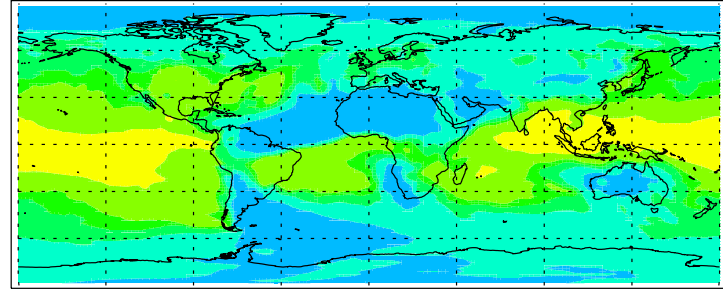

HP, coarse (\%)
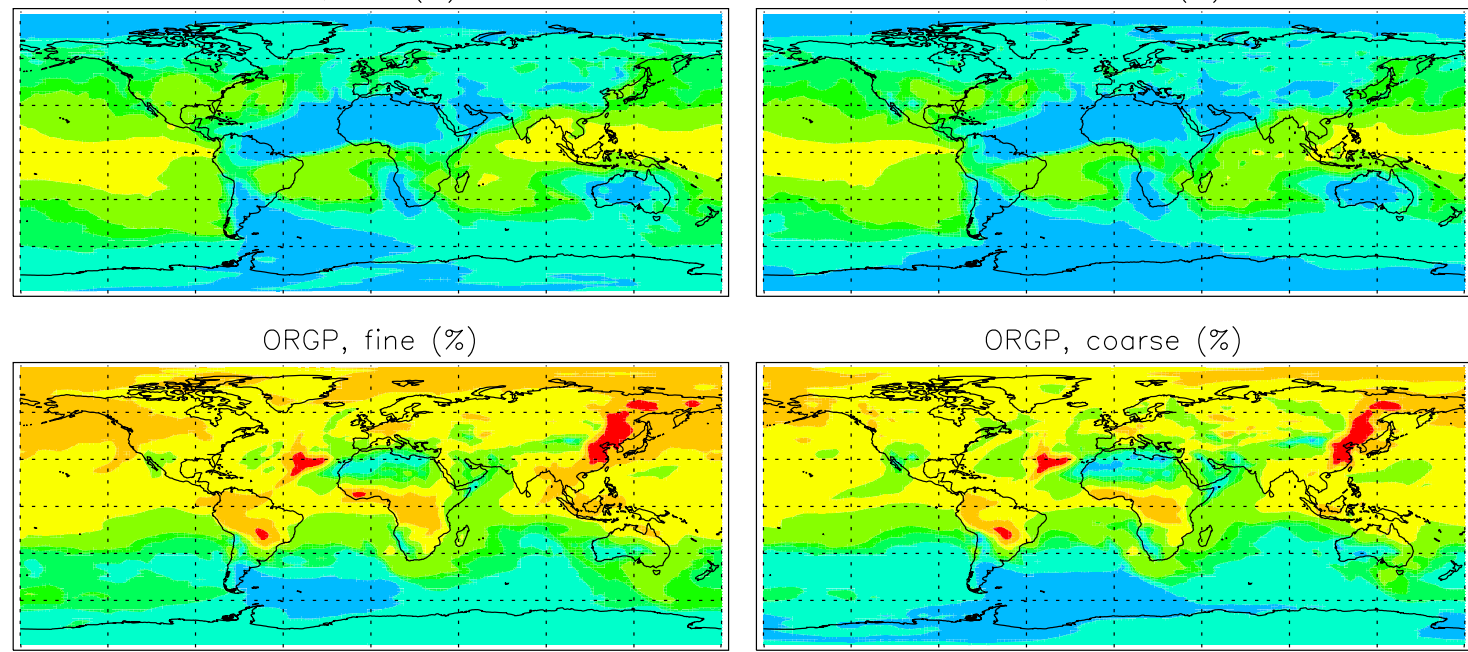

\subsection{0 \\ 0.10 \\ 0.50 \\ 1.00 \\ 1.50 \\ 2.00 \\ 5.00 \\ 10.00 \\ 20.00}

Figure 12. Global distribution of the modeled annually average percents of iron solubility $(\mathrm{Fe}(\mathrm{II}) / \mathrm{Fe} * 100)$ for each process. 

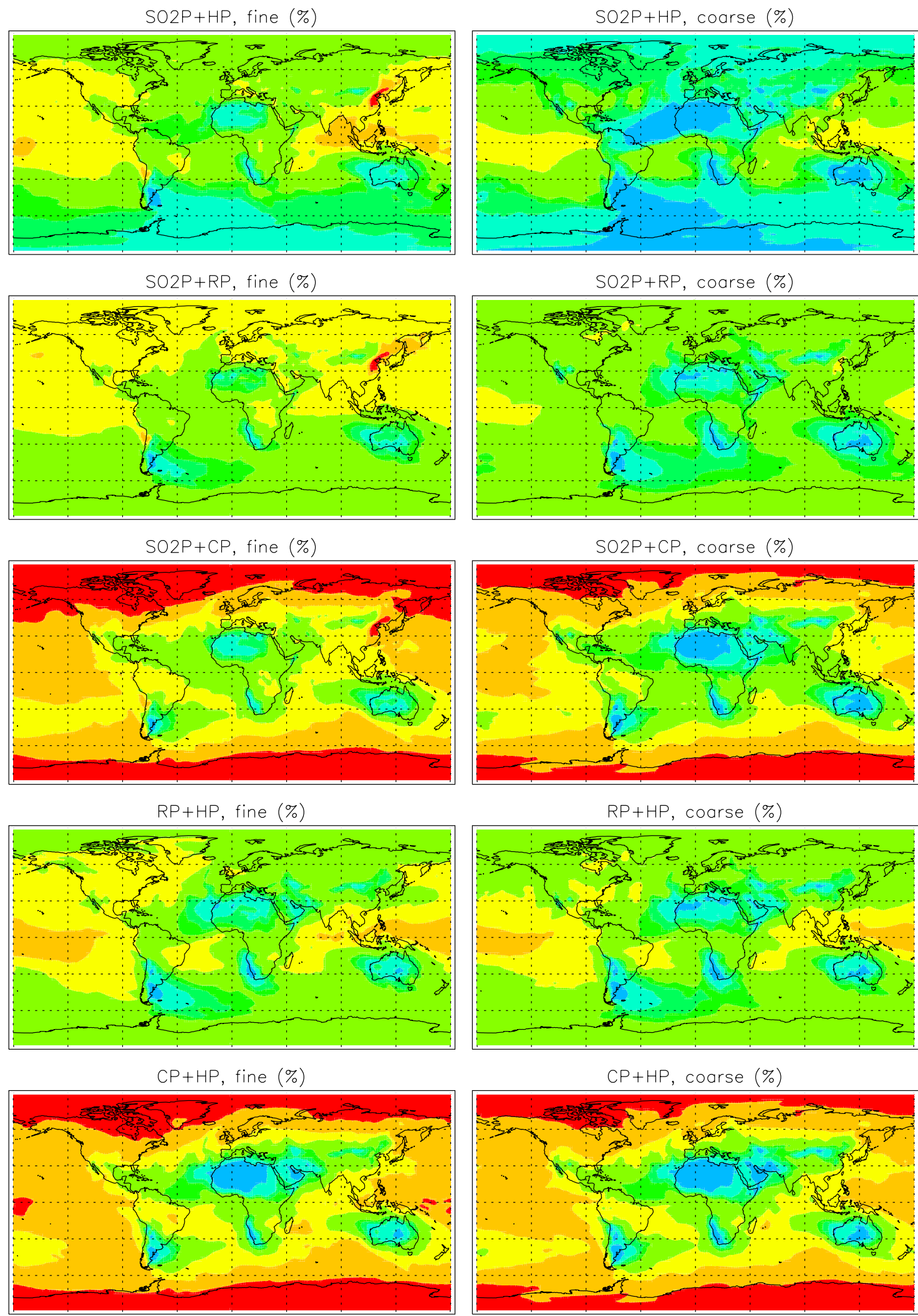

\subsection{0 \\ Figure 13. Similar to Figure 12, but for combined processes.}


Table 9. Correlation of Model $\mathrm{SO}_{4}$ and $\mathrm{OC}$ With $\mathrm{Fe}(\mathrm{II}) / \mathrm{Fe}$ for Each Cruise ${ }^{\mathrm{a}}$

\begin{tabular}{|c|c|c|c|c|c|c|c|c|c|c|c|c|}
\hline \multirow[b]{2}{*}{ Cruise } & \multicolumn{2}{|c|}{$\mathrm{CP}$} & \multicolumn{2}{|c|}{ RP } & \multicolumn{2}{|c|}{$\mathrm{SO} 2 \mathrm{P}$} & \multicolumn{2}{|c|}{ SO4P } & \multicolumn{2}{|c|}{ HP } & \multicolumn{2}{|c|}{ ORGP } \\
\hline & $\begin{array}{c}\text { SO4 } ~ \\
\text { Fesol }\end{array}$ & $\begin{array}{l}\text { oc } \sim \\
\text { Fesol }\end{array}$ & $\begin{array}{c}\text { SO4 } ~ \\
\text { Fesol }\end{array}$ & $\begin{array}{l}\text { oc } \sim \\
\text { Fesol }\end{array}$ & $\begin{array}{c}\text { SO4 } \\
\text { Fesol }\end{array}$ & $\begin{array}{l}\text { oc } \sim \\
\text { Fesol }\end{array}$ & $\begin{array}{c}\text { SO4 } \\
\text { Fesol }\end{array}$ & $\begin{array}{l}\text { oc } \sim \\
\text { Fesol }\end{array}$ & $\begin{array}{c}\text { SO4 } \\
\text { Fesol }\end{array}$ & $\begin{array}{l}\text { oc } \sim \\
\text { Fesol }\end{array}$ & $\begin{array}{c}\text { SO4 } ~ \\
\text { Fesol }\end{array}$ & $\begin{array}{l}\text { oc } \sim \\
\text { Fesol } \\
\end{array}$ \\
\hline MP01 & 0.54 & -0.60 & 0.10 & -0.54 & 0.21 & -0.38 & 0.54 & -0.49 & 0.17 & -0.55 & -0.32 & -0.10 \\
\hline MP02 & -0.30 & -0.46 & -0.30 & -0.26 & 0.77 & 0.77 & 0.79 & 0.81 & -0.17 & -0.13 & 0.75 & 0.75 \\
\hline MP03 & -0.30 & -0.32 & -0.10 & -0.30 & 0.05 & 0.02 & 0.08 & -0.24 & 0.26 & -0.17 & 0.02 & -0.30 \\
\hline MP05 & 0.06 & 0.22 & -0.06 & 0.02 & 0.09 & 0.13 & -0.07 & -0.07 & $-\mathbf{0 . 3 7}$ & -0.23 & 0.10 & -0.10 \\
\hline MP06 & -0.23 & -0.13 & 0.02 & -0.15 & -0.003 & -0.18 & 0.11 & -0.08 & 0.20 & 0.03 & -0.38 & -0.17 \\
\hline MP08 & -0.01 & 0.31 & 0.33 & 0.32 & -0.08 & -0.11 & 0.05 & 0.004 & -0.007 & 0.21 & 0.30 & 0.13 \\
\hline MP09 & 0.37 & 0.27 & 0.26 & 0.30 & 0.25 & 0.05 & 0.39 & 0.21 & 0.28 & 0.23 & 0.14 & 0.05 \\
\hline overall & 0.02 & -0.09 & 0.04 & -0.12 & 0.07 & 0.18 & 0.09 & -0.06 & -0.21 & 0.027 & -0.12 & 0.26 \\
\hline
\end{tabular}

${ }^{a}$ Values in bold are significant at $95 \%$.
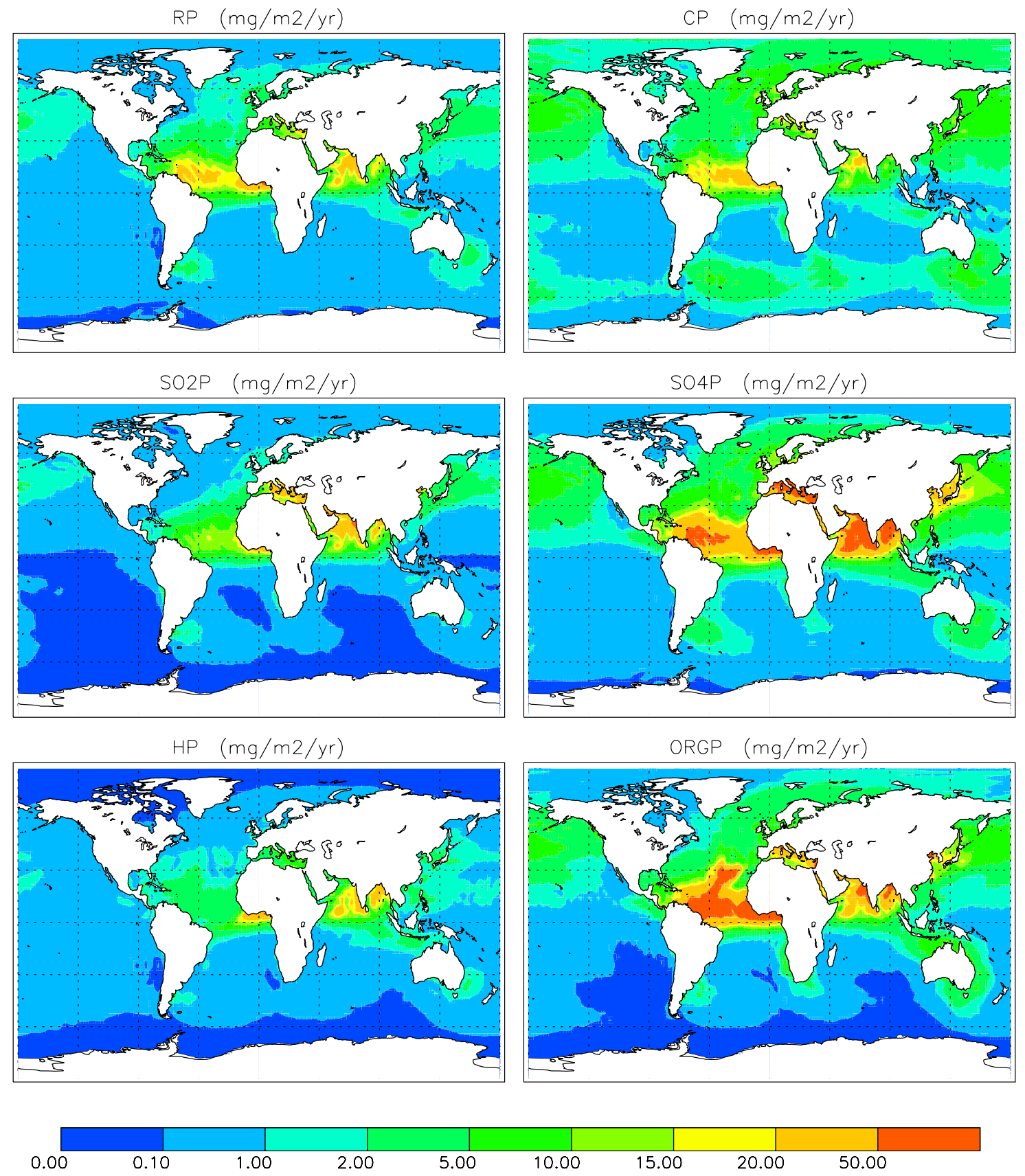

Figure 14. Soluble iron deposition (Fe(II)) over the global open oceans for the different processing cases, in units of $\mathrm{mg} \mathrm{m}^{-2} \mathrm{yr}^{-1}$. 
Table 10. Model Estimated Soluble Fe (Fe(II)) Deposited in Global Open Ocean ${ }^{a}$

\begin{tabular}{lcccrr}
\hline Process Basins & RP & CP & SO2P & SO4P \\
\hline N. Pacific & $6.42 \times 10^{7}$ & $1.82 \times 10^{8}$ & $4.67 \times 10^{7}$ & $2.31 \times 10^{8}$ & ORGP \\
S. Pacific & $2.57 \times 10^{7}$ & $6.95 \times 10^{8}$ & $7.88 \times 10^{6}$ & $4.16 \times 10^{7}$ & $2.48 \times 10^{7}$ \\
N. Atlantic & $2.09 \times 10^{8}$ & $2.29 \times 10^{8}$ & $1.26 \times 10^{8}$ & $4.98 \times 10^{8}$ & $5.56 \times 10^{7}$ \\
S. Atlantic & $2.68 \times 10^{7}$ & $4.58 \times 10^{7}$ & $1.24 \times 10^{7}$ & $5.40 \times 10^{7}$ & $2.14 \times 10^{7}$ \\
Indian Ocean & $9.14 \times 10^{7}$ & $6.21 \times 10^{7}$ & $9.43 \times 10^{7}$ & $4.04 \times 10^{8}$ & $4.01 \times 10^{7}$ \\
Antarctic & $2.58 \times 10^{6}$ & $1.70 \times 10^{7}$ & $5.76 \times 10^{5}$ & $3.26 \times 10^{6}$ & $1.08 \times 10^{8}$ \\
Arctic & $6.49 \times 10^{6}$ & $3.37 \times 10^{7}$ & $3.70 \times 10^{6}$ & $1.72 \times 10^{7}$ & $1.09 \times 10^{5}$ \\
Global & $5.61 \times 10^{8}$ & $8.45 \times 10^{8}$ & $3.81 \times 10^{8}$ & $1.63 \times 10^{9}$ & $3.08 \times 10^{5}$ \\
\hline
\end{tabular}

${ }^{\mathrm{a}}$ Units are in $\mathrm{kg} \mathrm{yr}^{-1}$.

Previously this was interpreted as evidence that these processes may not play an important role, perhaps because the atmosphere is largely acidic already [Hand et al., 2004]. However, in this study we show that even if sulfate is acting to convert $\mathrm{Fe}$ (III) to $\mathrm{Fe}(\mathrm{II})$ in the model, there is no significant correlation between sulfate and solubility. This is because the sulfur compounds are highest close to the source region, while the processed iron is higher downwind (after more processing has occurred). This makes concluding what processes dominate in the atmosphere difficult to deduce from observations of both species. More laboratory studies of the processes which convert iron to soluble iron are necessary to better constrain the solubilities deposited in different basins.

[41] Acknowledgments. This work was supported by NSFBiocomplexity (OCE-9981398) and NASA-IDS (NAG5-9671). Some of this work and most of the computer simulations were done at the National Center for Atmospheric Research (NCAR), which is sponsored by the National Science Foundation. We would like to thank the two anonymous reviewers for their fruitful comments.

\section{References}

Azuma, K., and H. Kametani (1964), Kinetics of dissolution of ferric oxide, Trans Metall. Soc AIME, 230, 853-862.

Baker, A. R. (2004), Inorganic iodine speciation in tropical Atlantic aerosol, Geophys. Res. Lett., 31, L23S02, doi:10.1029/2004GL020144.

Baker, A. R., S. D. Kelly, K. F. Biswas, M. Witt, and T. D. Jickells (2003), Atmospheric deposition of nutrients to the Atlantic Ocean, Geophys. Res. Lett., 30(24), 2296, doi:10.1029/2003GL018518.

Baker, A. R., T. D. Jickells, M. Witt, and K. L. Linge (2005), Trends in the solubility of iron, aluminum, manganese and phosphorus in aerosol collected over the Atlantic Ocean, Mar. Chem., in press.

Barbeau, K., E. Rue, K. Bruland, and A. Butler (2001), Photochemical cyclng of iron in the surface ocean mediated by microbial iron (III)-binding ligands, Nature, 413, 409-413.

Barth, M. C., P. J. Rasch, and J. T. Kiehl (2000), Sulfur chemistry in National Center for Atmospheric Research Community Climate Model: Description, evaluation features, and sensitivity to aqueous chemistry, J. Geophys. Res., 105, 1387-1415.

Benkovitz, C. M., M. T. Scholtz, J. Pacyna, L. Tarrason, J. Dignon, E. C. Voldner, P. A. Spiro, J. A. Logan, and T. E. Graedel (1996), Global gridded inventories of anthropogenic emissions of sulfur and nitrogen, J. Geophys. Res., 101, 29,239-29,254

Blesa, M. A., P. J. Morando, and A. E. Regazzoni (1994), Chemical Dissolution of Metal Oxides, 401 pp., CRC Press, Boca Raton, Fla.

Bonan, G. B. (1996), A land surface model (LSM version 1.0) for ecological, hydrological, and atmospheric studies: Technical description and user's guide, Tech Rep. NCAR/TN-417+STR, Natl. Cent. for Atmos. Res., Boulder, Colo.

Boyle, E., B. Bergquist, R. Kayser, and N. Mahowald (2005), Iron, manganese and lead at Hawaii ocean time-series station ALOHA: Temporal variability and an intermediate water hydrothermal plume, Geochim. Cosmochim. Acta, 69(4), doi:10.1016/j.gca.2004.07.034, 933-952.

Cama, J., C. Ayora, and A. C. Lasaga (1999), The deviation-fromequilibrium effect on dissolution rate and on apparent variations in activation energy, Geochim. Cosmochim. Acta, 63(17), 2481-2486.
Charlson, R. J., J. E. Lovelock, M. O. Andreae, and S. G. Warren (1987), Oceanic phytoplankton, atmospheric sulphur, cloud albedo and climate, Nature, 326, 655-661.

Chen, Y., and R. L. Siefert (2003), Determination of various types of labile atmospheric iron over remote oceans, J. Geophys. Res., 108(D24), 4774, doi:10.1029/2003JD003515.

Chen, Y., and R. L. Siefert (2004), Seasonal and spatial distributions and dry deposition fluxes of atmospheric total and labile iron over the tropical and subtropical North Atlantic Ocean, J. Geophys. Res., 109, D09305, doi:10.1029/2003JD003958.

Cooper, D. J., A. J. Waterson, and P. D. Nightingale (1996), Large decrease in ocean-surface $\mathrm{CO}_{2}$ fugacity in response to in situ iron fertilization, Nature, 383, 511-513.

Cornell, R. M., and U. Schwertmann (1996), The Iron Oxides, Structure, Properties, Reactions, Occurrence and Uses, 573 pp., John Wiley, Hoboken, N. J.

Dentener, F. J., and P. J. Crutzen (1993), Reaction of $\mathrm{N}_{2} \mathrm{O}_{5}$ on tropospheric aerosols: Impact on the global distributions of $\mathrm{NO}_{\mathrm{x}}, \mathrm{O}_{3}$, and $\mathrm{OH}$, J. Geophys. Res., 98, 7149-7163.

Duce, R. A., and N. W. Tindale (1991), Atmospheric transport of iron and its deposition in the ocean, Limnol. Oceanogr., 36(8), 1715-1726.

Falkowski, P. G., R. T. Barber, and V. Smetacek (1998), Biogeochemical controls and feedbacks on ocean primary production, Science, 281, 200206.

Fecan, F., B. Marticorena, and G. Bergametti (1999), Parameterization of the increase of the Aeolian erosion threshold wind friction velocity due to soil moisture for arid and semi-arid area, Ann. Geophys., 17, 149-157.

Fung, I. Y., S. K. Meyn, I. Tegen, S. C. Doney, J. G. John, and J. K. B. Bishop (2000), Iron supply and demand in the upper ocean, Global Biogeochem. Cycles, 14, 281-295.

Gillette, D. A., and R. Passi (1988), Modeling of dust emission caused by wind erosion, J. Geophys. Res., 93, 14,223-14,242.

Gillette, D. A., E. Hardebeck, and J. Parker (1997), Large-scale variability of wind erosion mass flux rates at Owens Lake: 2. Role of roughness change, particle limitation, change of threshold friction velocity, and the Qwen effect, J. Geophys. Res., 102, 25,989-25,998.

Ginoux, P., M. Chin, I. Tegen, J. Prospero, B. Holben, O. Dubovik, and S. J. Lin (2001), Sources and distributions of dust aerosols simulated with the GOCART model, J. Geophys. Res., 106, 20,255-20,273.

Guelle, W., Y. J. Balkanski, M. Schulz, B. Marticorena, G. Bergametti, C. Moulin, R. Arimoto, and K. D. Perry (2000), Modeling the atmospheric distribution of mineral aerosol: Comparison with ground measurements and satellite observations for yearly and synoptic timescales over the North Atlantic, J. Geophys. Res., 105, 1997-2012.

Hand, J. L., N. Mahowald, Y. Chen, R. Siefert, C. Luo, A. Subramaniam, and I. Fung (2004), Estimates of soluble iron from observations and a global mineral aerosol model: Biogeochemical implications, J. Geophys. Res., 109, D17205, doi:10.1029/2004JD004574.

Husar, R. B., J. M. Prospero, and L. L. Stowe (1997), Characterization of tropospheric aerosols over the oceans with the NOAA advanced very high resolution radiometer optical thickness operational product, J. Geophys. Res., 102, 16,890-16,909.

Iversen, J. D., and B. R. White (1982), Saltation threshold on Earth, Mars and Venus, Sedimentology, 29, 111-119.

Johansen, A. M., R. L. Siefert, and M. R. Hoffman (2000), Chemical composition of aerosols collected over the tropical North Atlantic Ocean, J. Geophys. Res., 105, 15,277-15,312.

Kistler, R., et al. (2001), The NCEP-NCAR 5-year reanalysis: Monthly means CD-ROM and documentation, Bull. Am. Meteorol. Soc., 82(2), $247-267$

Lasaga, A. C., J. M. Soler, J. Ganor, T. E. Burch, and K. L. Nagy (1994), Chemical-weathering rate laws and global geochemical cycles, Geochim. Cosmochim. Acta, 58(10), 2361-2386. 
Lefevre, N., and A. J. Waterson (1999), Modeling the geochemical cycle of iron in the oceans and its impact on atmospheric $\mathrm{CO}_{2}$ concentrations, Global Biogeochem. Cycles, 13(3), 727-736.

Luo, C., N. Mahowald, and J. del Corral (2003), Sensitivity study of meteorological parameters on mineral aerosol mobilization, transport, and distribution, J. Geophys. Res., 108(D15), 4447, doi:10.1029/ 2003JD003483.

Mahowald, N., and J.-L. Dufresne (2004), Sensitivity of TOMS AI to PBLH: Implications for detection of mineral aerosol sources, Geophys. Res. Lett., 31, L03103, doi:10.1029/2003GL018865.

Mahowald, N., and C. Luo (2003), A less dusty future?, Geophys. Res. Lett., 30(17), 1903, doi:10.1029/2003GL017880.

Mahowald, N. M., P. J. Rasch, B. E. Eaton, S. Whittleston, and R. G. Prinn (1997), Transport of 222 Radon to the remote troposphere using MATCH and assimilated winds from ECMWF and NCEP/NCAR, J. Geophys. Res., 102(D23), 28,139-28,151.

Mahowald, N., K. Kohfeld, M. Hansson, Y. Balkanski, S. P. Harrison, I. C. Prentice, M. Schulz, and H. Rodhe (1999), Dust sources and deposition during the last glacial maximum and current climate: A comparison of model results with paleodata from ice cores and marine sediments, J. Geophys. Res., 104, 15,895-15,916.

Mahowald, N., C. Zender, C. Luo, D. Savoie, O. Torres, and J. D. Corral (2002), Understanding the 30-year Barbados desert dust record, J. Geophys. Res., 107(D21), 4561, doi:10.1029/2002JD002097.

Mahowald, N., A. Baker, G. Bergametti, N. Brooks, R. Duce, T. Jickells, N. Kubilay, J. Prospero, and I. Tegen (2005), The atmospheric global dust cycle and iron inputs to the ocean, Global Biogeochem. Cycles, doi:10.1029/2004GB002402, in press.

Marticorena, B., and G. Bergametti (1995), Modeling the atmospheric dust cycle: 1. Design of a soil-derived dust emission scheme, J. Geophys. Res., 100(D8), 16,415-16,430.

Martin, J. H., R. M. Gordon, and S. E. Fitzwater (1991), The case for iron, Limnol. Oceanogr., 36, 1793-1802.

Meskhidze, N., W. L. Chameides, A. Nenes, and G. Chen (2003), Iron mobilization in mineral dust: Can anthropogenic $\mathrm{SO}_{2}$ emissions affect ocean productivity?, Geophys. Res. Lett., 30(21), 2085, doi:10.1029/ 2003GL018035.

Meskhidze, N., A. Nenes, W. Conant, and J. Seinfeld (2005), Evaluation of a new cloud droplet activation parameterization with in situ data from CRYSTAL-FACE and CSTRIPE, J. Geophys. Res., 110, D16202, doi:10.1029/2004JD005703.

Pehkonen, S. O., R. Siefert, Y. Erel, S. Webb, and M. R. Hoffman (1993), Photoreduction of iron oxyhydroxides in the presence of important atmospheric organic compounds, Environ. Sci. Technol., 27, 2056-2062.

Prospero, M. J., P. Ginoux, O. Torres, and S. E. Nicholson (2002), Environmental characterization of global sources of atmospheric soil dust derived from the NIMBUS-7 TOMS absorbing aerosol product, Rev Geophys., 40(1), 1002, doi:10.1029/2000RG000095.

Raes, F., et al. (2000), Formation and cycling of aerosols in the global troposphere, Atmos. Environ., 34, 4215-4240.

Rasch, P. J., N. M. Mahowald, and B. E. Eaton (1997), Representation of transport, convection, and hydrologic cycle in chemical transport models: Implications for the modeling of short-lived and soluble species, J. Geophys. Res., 102(D23), 18,127-18,138.

Rasch, P. J., J. Feichter, K. Law, N. M. Mahowald, and J. Penner (2000), A comparison of scavenging and deposition processes in global models: Results from the WCRP Cambridge Workshop of 1995, Tellus, Ser. B, 52, 1025-1056.

Sarthou, G., et al. (2003), Atmospheric iron deposition and sea-surface dissolved iron concentrations in the eastern Atlantic Ocean, Deep Sea Res., Part I, 50, 1336-1352.

Saydam, A. C., and H. Z. Senyuva (2002), Deserts: Can they be the potential supplies of bioavailable iron?, Geophys. Res. Lett., 29(11), 1524 doi:10.1029/2001GL013562.

Seinfeld, J., and S. Pandis (1996), Atmospheric Chemistry and Physics: From Air Pollution to Climate Change, John Wiley, Hoboken, N. J.

Siefert, R. L., S. O. Pehkonen, Y. Erel, and M. R. Hoffman (1994), Iron photochemistry of aqueous suspensions of ambient aerosol with added organic acids, Geochim. Cosmochim. Acta, 58, 3271-3279.

Siefert, R. L., A. M. Johansen, M. R. Hoffmann, and S. O. Pehkonen (1997), Measurements of trace metal ( $\mathrm{Fe}, \mathrm{Cu}, \mathrm{Mn}, \mathrm{Cr}$ ) oxidation states in fog and stratus clouds, J. Air Waste Manage. Assoc., 48, 128-143.

Siefert, R. L., A. M. Johansen, and M. R. Hoffman (1999), Chemical characterization of ambient aerosol collected during the southwest mon- soon and intermonsoon seasons over the Arabian Sea: Labile-Fe(II) and other trace metals, J. Geophys. Res., 104, 3511-3526.

Sillanpaa, M. (1982), Micronutrients and nutrient status of soil, a global study, FAO, Soil Bull., 48, Rome.

Skopp, J. M. (2000), Physical properties of primary particles, in Handbook of Soil Science, edited by M. E. Summer, pp. 3-17, CRC Press, Boca Raton, Fla.

Stookey, L. L. (1970), Ferrozine-A new spectrophotometric reagent for iron, Anal. Chem., 42, 119-781.

Stumm, W., and J. J. Morgan (Eds.) (1981), Aquatic Chemistry: An Introduction Emphasizing Chemical Equilibria in Natural Waters, 780 pp., John Wiley, Hoboken, N. J.

Tegen, I., and I. Fung (1994), Modeling of mineral dust in the atmosphere: Sources, transport, and optical thickness, J. Geophys. Res., 99, 22,89722,914 .

Tegen, I., S. P. Harrison, K. E. Kohfeld, I. C. Prentice, M. C. Coe, and M. Heimann (2002), Impact of vegetation and preferential source areas on global dust aerosol: Results from a model study, J. Geophys. Res., 107(D21), 4576, doi:10.1029/2001JD000963.

Tegen, I., M. Werner, S. P. Harrison, and K. E. Kohfeld (2004), Relative importance of climate and land use in determining present and future global soil dust emission, Geophys. Res. Lett., 31, L05105, doi:10.1029/2003GL019216.

Turner, S. M., P. D. Nightingale, L. J. Spokes, M. I. Liddicoat, and P. S. Liss (1996), Increased dimethyl sulphide concentrations in sea water from in situ iron enrichment, Nature, 383, 513-517.

Watson, A. J., C. S. Law, K. A. Van Scoy, F. J. Millero, W. Yao, G. E. Friederich, M. I. Liddicoat, R. H. Wanninkhof, R. T. Barber, and K. H. Coale (1994), Minimal effect of iron fertilization on sea-surface carbon dioxide concentrations, Nature, 371, 143-145.

Zender, C., H. Bian, and D. L. Newman (2003), Mineral Dust Entrainment and Deposition (DEAD) model: Description and 1990s dust climatology, J. Geophys. Res., 108(D14), 4416, doi:10.1029/2002JD002775.

Zhu, X., J. M. Prospero, F. J. Millero, D. L. Savoie, and G. W. Brass (1992), The solubility of ferric iron in marine mineral aerosol solutions at ambient relative humidities, Mar. Chem., 38, 91-107.

Zhu, X., J. M. Prospero, D. L. Savoie, F. J. Millero, R. G. Zika, and E. S. Saltzman (1993), Photoreduction of iron(III) in marine mineral aerosol solutions, J. Geophys. Res., 98, 9039-9046.

Zhu, X., J. M. Prospero, and F. J. Millero (1997), Diel variability of soluble $\mathrm{Fe}(\mathrm{II})$ and soluble total $\mathrm{Fe}$ in North African dust in the trade winds at Barbados, J. Geophys. Res., 102, 21,297-21,305.

Zhuang, G., R. A. Duce, and D. R. Kester (1990), The dissolution of atmospheric iron in surface seawater of the open ocean, J. Geophys. Res. 95, 16,207-16,216

Zhuang, G., Z. Yi, R. A. Duce, and P. R. Brown (1992), Link between iron and sulphur cycles suggested by detection of $\mathrm{Fe}(\mathrm{II})$ in remote marine aerosols, Nature, 355, 537-539.

Zinder, B., G. Furrer, and W. Stumm (1986), The coordination chemistry of weathering: II. Dissolution of Fe(III) oxides, Geochim. Cosmochim. Acta, $50(9), 1861-1869$

Zuo, Y. (1995), Kinetics of photochemical/chemical cycling of iron coupled with organic substances in cloud and fog droplets, Geochim. Cosmochim. Acta, 59, 3123-3130.

Zuo, Y., and J. Hoigne (1992), Formation of hydrogen peroxide and depletion of oxalic acid in atmospheric water by photolysis of iron (III)-oxalato complexes, Environ. Sci. Technol., 26, 1014-1022.

A. R. Baker, School of Environmental Science, University of East Anglia, Norwich NR4 7TJ, UK.

Y. Chen and R. L. Siefert, Chesapeake Biological Laboratory, University of Maryland Center for Environmental Science, Solomons, MD 20688 , USA.

A. M. Johansen, Department of Chemistry, Central Washington University, Ellensburg, WA 98926, USA.

C. Luo, Institute for Computational Earth System Science, University of California, Santa Barbara, CA 93106, USA. (chaoluo@bren.ucsb.edu)

N. M. Mahowald, National Center for Atmospheric Research, Boulder, CO 80305, USA.

N. Meskhidze, School of Earth and Atmospheric Science, Georgia Institute of Technology, Atlanta, GA 30332, USA. 